\title{
The Dog That Did Not Bark: Insider Trading and Crashes*
}

\author{
Jose M. Marin ${ }^{\dagger}$ \\ Jacques Olivier ${ }^{\ddagger}$
}

March 2, 2006

\begin{abstract}
This paper documents that at the individual stock level insiders sales peak many months before a large drop in the stock price, while insiders purchases peak only the month before a large jump. We provide a theoretical explanation for this phenomenon based on trading constraints and asymmetric information. We test our hypothesis against competing stories such as patterns of insider trading driven by earnings announcement dates, or insiders timing their trades to evade prosecution. Finally we provide new evidence regarding crashes and the degree of information asymmetry.
\end{abstract}

Journal of Economic Literature Classification Numbers: D82, G11, G12, G14, G28 Keywords: Insider Trading, Rational Expectations Equilibrium, Trading Constraints, Volatility, Crashes.

\footnotetext{
${ }^{*}$ We are very grateful to Antoni Sureda for outstanding research assistance and to Anthony Tay for helpful pointers early in the project. We also thank Joachim Voth for very insightful comments and seminar audiences at the SAET 2005 Meeting, Pompeu Fabra University and University of Alicante. Jose Marin acknowledges financial support from the Spanish Ministry of Science and Technology (BEC2002-00429 Grant) and from CREA. Jacques Olivier gratefully acknowledges financial support from the Fondation HEC.

${ }^{\dagger}$ Universitat Pompeu Fabra and CREA; E-mail:jose.marin@upf.edu

${ }^{\ddagger}$ H.E.C. School of Management, GREGHEC and CEPR; E-mail: olivier@hec.fr
} 


\section{INTRODUCTION}

Sir Arthur Conan Doyle made clear in his celebrated "Silver Blaze" mystery that sometimes there is more to be learned from the absence of an action than from its presence. This insight turns out very relevant in the present first study of the patterns of insider trading preceding large movements in stock prices. Figure 1 is illustrative of the type of phenomena we study. The figure shows the sales and purchases done by corporate managers in the 12 months preceding, respectively, the largest drop and the largest jump in the monthly S\&P 500 index during the 1986-2005 period. It can be observed that aggregate sales by insiders peaked ten months before the drop and then went down sharply before the drop occurred. By way of contrast, aggregate purchases by insiders before the jump exhibit a very different pattern: they remained low all year long and picked up only the month before the jump. In the paper, we look at individual stocks traded on the NYSE, AMEX and NASDAQ between 1985 and 2002 and find evidence of similar patterns of insider trading preceding large events at the individual stock level. The evidence is especially strong regarding insider sales, which runs against the mainstream view that insider sales are almost exclusively driven by the needs for liquidity and diversification.

[Insert figure 1]

Why would insiders sell many months before a large drop but stop selling soon before the event? There are many possible answers to this question. One view is that many large drops in prices are due to companies failing to meet earnings expectations and that most companies prohibit insiders from trading prior to an earning announcement ${ }^{1}$. Thus, any insider who wishes to exploit private information related to poor company earnings has to trade significantly before the actual earnings announcement and, therefore, significantly before the crash. Another view is that insiders try to es-

\footnotetext{
${ }^{1}$ The Insider Trading and Securities Enforcement Act of 1988 made top management responsible for insider trading done by any employee. This regulation encouraged companies to issue internal rules prohibiting all trading by insiders around major corporate events, such as earning announcements or take-over deals.
} 
cape scrutiny from the SEC and that the SEC investigates any trade that takes place near the date at which the price movement occurred. A third alternative view is that insiders are forced to trade many months before the expected price drop because of the "short swing" rule of the 1934 Security Exchange Act that prohibits profit-taking by insiders for offsetting trades within six months ${ }^{2}$. In either case, insiders who wish to profit from their private information will optimally trade months before the date of the actual event.

It is hard, however, to reconcile any of these views of the evidence on insider sales with the evidence on insider purchases. Why don't we observe a similar pattern of insider purchases prior to jumps? It is indeed the sharp asymmetry between sales before crashes and purchases before jumps that is hard to reconcile with any theory that treats both types of transactions symmetrically. In our view, these two types of transactions are not symmetric because of portfolio constraints faced by insiders when they trade on bad news. These constraints may arise for several reasons, such as shortselling constraints ${ }^{3}$, the insider being a large shareholder who wishes to retain control of the company, or the insider being a manager who is granted some stocks as part of his compensation package but which he is not allowed to resale before some period of time. In the first part of the paper we address this conjecture theoretically and show that the presence of such portfolio constraints can explain both the occurrence of crashes and the observed pattern of insider trading. We then test our model and compare its predictions with those of competing stories in the second part of the paper.

The model we use is a standard noisy rational expectations model à la Grossman

\footnotetext{
${ }^{2}$ For an analysis of returns to insider trading based on the six months short swing rule, see Jeng et al. (2003).

${ }^{3}$ The short selling restrictions for individual investors in the US are fairly mild and stem mostly from the up-tick rule and from the extra cost for borrowing securities. On the other hand, the restrictions for corporate insiders are much more stringent. Section 16c of the Securities and Exchange Act prohibits US insiders to sell short their own stock. Furthermore, new regulations in the 1980's assure this requirement can not be evaded by creating a similar position by trading in derivatives. Allowing insiders to sell short would not be in the interest of shareholders as it would miss-align shareholders and management interests.
} 
and Stiglitz (1980) and Bhattacharya and Spiegel (1991), but where trading by informed traders is restricted in that their stock holdings cannot go below a given floor. Whenever insiders are trading, information gets incorporated into prices and prices adjust continuously. However, once insiders' holdings reach the floor set by the constraint, insiders can no longer act on further bad news. When uninformed traders observe past trading by insiders which is consistent with their constraint being binding, they can infer only that insiders are in possession of bad news (as otherwise insiders would be buying the stock back) but not how bad the news really are. This deductive process results on a sharp change in outside investors beliefs and perceived level of uncertainty. In particular, expected payoffs fall and uncertainty (risk) rises. The combination of the two effects leads to a discontinuity in the price process, that is a crash. However, to the extent that the crash is driven by a drop in the informational content of prices and an increase of the risk premium required by uninformed investors, it is consistent with agents rationality and with stock market efficiency.

This theory of crashes in asset prices exhibit two main distinctive features, which give rise to testable implications. The first feature is that compared to normal times, crashes occur after insiders' holdings have reached a floor and are preceded by an immediate period of relatively low insider trading activity. Thus, insider sales in the immediate past should be associated to a low likelihood of a crash (since in our model a crash occurs after the insiders have stopped trading) but insider sales in the far past should be associated to a high likelihood of a crash (since it brings insiders closer to the point where the "floor" constraint binds). The second feature is that a symmetric pattern of insider purchases, namely a period of intense purchases followed by a period relatively low activity, does not generate a jump in the stock price. This is because there is no "ceiling" constraint on insiders holdings to mirror the "floor" constraint. As mentioned earlier, the second feature is what distinguishes the testable implications of our model with those of theories based on insiders trying to evade prosecution or based on the short swing rule. We test our theory using a dataset similar to the one used by Lakonishok and Lee (2001), covering the insider trading activity of companies 
traded on the NYSE, AMEX and NASDAQ during the 1985-2002 period. The empirical results provide strong support for both distinctive features of our theoretical model. The results are robust to splitting the sample and to the use of different estimation techniques, different measures of crashes and different time periods for the insider trading variables.

Our work is related to two lines of research in finance: insider trading and stock market crashes. A key issue in the literature on insider trading is whether insiders earn abnormal returns on their portfolios. The answer provided by most recent empirical analysis is that stocks purchased by insiders earn positive abnormal returns but stocks sold by insiders do not exhibit negative abnormal returns. Lakonishok and Lee (2001) look at abnormal returns of portfolios based on the intensity of insider purchases and sales. After controlling for size, book to market and momentum effects, they find a statistically and economically significant excess return of $4.82 \%$ for portfolios of stocks with a strong "purchase signal". By way of contrast, the excess return of strong "sell signals" portfolios is statistically insignificant. Jeng et al. (2003) estimate the returns to the insiders' own portfolio over a six-month window. They construct a "purchase portfolio" that holds all shares purchased by insiders over a six month period and a "sale portfolio" that holds all shares sold by insiders over a six month period. They find that the purchase portfolio earns positive abnormal returns of the order of 50 basis points per month while the sale portfolio earns no negative abnormal return. Friederich et al. (2002) and Fidrmuc et al. (2004) provide evidence based on UK data suggestive of significantly smaller absolute price reaction to insider sales than to insider purchases. Thus, the consensus of the existing literature when interpreting these results is that "insider selling that is motivated by private information is dominated by portfolio rebalancing for diversification purposes" (Lakonishok and Lee (2001))

In this paper, we provide new evidence regarding the informational content of insider sales. Using insights from our model, we argue that the coefficient of insider sales in a typical regression explaining returns is theoretically indeterminate even when insider sales are informationally driven. On the one hand, selling by insiders reveals bad news 
to the market and causes prices to go down. On the other hand, the absence of selling by insiders can reveal even worse news (the "dog that did not bark" effect) and thus cause prices to go down even more rapidly than if there had been moderate selling by insiders. The first effect tends to make the coefficient of insider sales negative while the second effect tends to make it positive. In the empirical part of this paper we use insiders sales and purchases to explain extreme returns (crashes and jumps) rather than returns per se, as in the existing literature on insider trading. We find that insider sales are very significantly associated with crashes, in a way both consistent with our theory and inconsistent with the hypothesis that insider sales are solely driven by liquidity needs.

The second branch of the literature our work is related to deals with stock market crashes. The past few years have seen an explosion of research providing insightful analysis of why and how crashes can occur. It turns out useful to split this literature in two families, depending on whether crashes are associated with higher or lower uncertainty from the point of view of uninformed traders. In the first category category we have, first, models that view crashes as bursting bubbles ${ }^{4}$, all of which imply that a crash brings prices closer to fundamental values. Models based on rational herding ${ }^{5}$ will deliver a similar prediction. Finally, in this category we also have a number of models that emphasize the role played by trading constraints, most notably Romer (1993), Cao et al. (2002) and Hong and Stein (2003), that predict that crashes reveal information as they are driven by informed investors who were initially out of market getting back into the market (sidelined investors). Interestingly enough, trading constraints also play a crucial role in models belonging to the second family, where crashes are not driven by revelation of information but, on the contrary, by a sharp increase in uncertainty. Models belonging to the second family comprise work by Gennotte and Leland (1990), Barlevy and Veronesi (2003) and by Yuan (2005). Our model also belongs to this category with two differences relative to the existing literature. First, from a technical

\footnotetext{
${ }^{4}$ See for instance Allen et al. (1993), Allen and Gale (2000) Allen et al. (2003) and Hong et al. $(2005)$

${ }^{5}$ For instance, see Devenou and Welch (1996) for an early survey.
} 
point of view, we eliminate some unnecessary ingredients of existing models, such as ad-hoc trading rules and borrowing or leverage constraints. Second, and more crucially, we let trading by informed investors to be observable by the rest of the market. This feature is important to bring the model to the data since we wish to identify informed investors as insiders, whose trades are publicly observable in markets such as the US market.

Thus, a key variable for sorting among the many different views of crashes is whether crashes are associated with informed investors getting in the market and prices becoming more informative, or whether crashes are associated with informed investors getting out of the market and prices becoming less informative. Our empirical work allows us to shed some light on this issue in the context of the US markets in the past 20 years. There is data available on the actual trading of one type of informed investors, namely insiders, and we can easily construct different indicators of crashes at the individual stock level. Thus we can test whether insiders have been pulling in or out of the market prior to a crash. The results we obtain unambiguously supports the view of crashes associated with informed investors pulling out of the market. Indeed we find that both insiders trading volume and insiders sales are negatively and significantly associated with the likelihood of a crash in the following month. We also find that these two variables are positively and significantly associated with the likelihood of a crash in the following year. In other words, the highest likelihood of a crash is obtained when there has been selling by insiders in the past but insiders have just pulled out of the market ${ }^{6}$

A closely related paper to our empirical analysis is the work by Chen et al. (2001). They look at the determinants of negative skewness in individual stock returns. They estimate negative skewness using daily returns and find that it is most pronounced in stocks where trading volume has recently gone up and in stocks with positive returns

\footnotetext{
${ }^{6} \mathrm{~A}$ totally different way to test between these two hypothesis would consist in looking at the implications for expected returns. If a crash is an event that reveals information, one would expect the risk premium demanded by uninformed investors to go down after the crash. By way of contrast, if a crash is an event where prices reveal less information, one would expect the risk premium required by uninformed investors to go up after the crash.
} 
over the past 36 months. The first finding supports the view that more heterogeneity of beliefs is conductive to crashes, as emphasized in Hong and Stein (2003). The second finding is consistent with a number of models, most notably models with stochastic bubbles. One difference between Chen, Hong and Stein's empirical analysis and ours is that we use a binary indicator of crashes instead of using negative skewness. Our results are an indication of the robustness of Chen, Hong and Stein's findings since we also find that both past returns and the change in total trading volume are positively associated with a higher likelihood of crashes. However, the main difference between our work and Chen, Hong and Stein's is that we look not only at the impact of total trading volume on crashes but also at the impact of insider trading on crashes, which allows us to test whether a well-defined group of investors with superior information gets into or out of the market before a crash.

The reminder of the paper is organized as follows. In section 2 we present a theoretical model of insider trading in the presence of trading constraints. Section 3 is dedicated to the empirical study. We first describe the data, define the variables and explain the methodology. Then we empirically test the main predictions of the model. We also conduct additional tests supporting our model of insiders' behavior in the presence of trading constraints over competing stories of insiders' behavior. Finally, section 4 is dedicated to some concluding remarks.

\section{A SIMPLE MODEL OF INSIDER TRADING AND CRASHES}

In this section we define a simple environment of insider trading. The model is simple but rich enough to identify some testable implications of insider trading activity on asset prices. In this framework "insiders" have access to private information on asset payoffs and can trade with uninformed traders on the basis on that information. They can also trade due to hedging needs. All agents have rational expectations and in equilibrium prices are partially revealing. In this simple setting we show that when 
insiders face some realistic trading constraints (such us not being able to sell short shares of the stock) assets prices exhibit price discontinuities, or crashes. Furthermore, the model identifies a very specific pattern of insiders' stock holdings around those crashes. In section 4 we test some of the predictions of this model.

\subsection{The Basic Assumptions}

The following setting of asset trading is a generalization of the Grossman and Stiglitz (1980) model to introduce a constraint on asset holding. The other deviation from the Grossman and Stiglitz (1980) setting consists on substituting "noise" by trading arising from agents' hedging needs ${ }^{7}$. More formally, there is an underlying probability space $(\Omega, \mathcal{F}, \mathbf{P})$, on which all random variables are defined. A state of nature is denoted by $\omega \in \Omega$. It is further assumed that all random variables belong to a linear space $\mathcal{N}$ of joint normally distributed random variables on $\Omega$. We will omit the dependance on $\omega$ whenever it does not lead to confusion. The economy lasts for one period. At the beginning of the period agents trade in the asset market. At the end of the period all uncertainty is resolved and agents consume the only good in the economy whose price is normalized to one. There are two assets in the economy: a risk-free and a risky asset. The risk-free asset has a perfectly elastic supply and, without loss of generality, offers a rate of return equal to zero. The risky asset consists on shares of a company. There is a per capita amount of $\bar{n}>0$ shares outstanding each of which offers a payoff given by the (normally distributed) random variable $f: \Omega \rightarrow \Re$,

$$
f=\bar{f}+y+\epsilon
$$

where $y$ and $\epsilon$ are normally distributed random variables and $\bar{f}$ is a constant. There is a unit mass of traders in the economy. A fraction $\lambda_{I}$ are "insiders" who have some private information which is statistically related to $f$. In particular, each insider is in a position that allows him to learn $y$, one of the components of the risky asset payoff. Each insider is endowed with $\bar{n}_{I}$ shares of the risky asset. The remaining fraction,

\footnotetext{
${ }^{7}$ For instance, see Marin and Rahi (2000) for some of the implications of this source of trading on asset pricing and financial innovation.
} 
$\left(1-\lambda_{I}\right)$ of agents do not receive any private information and we will often refer to them as "uninformed" traders ${ }^{8}$. Each uninformed trader is endowed with $\bar{n}_{U}$ shares of the risky asset.

Agents also receive income $e_{i}: \Omega \rightarrow \Re$ at the end of the period. This income can either be interpreted as labor income or just income from holding assets which do not have a spot market for trading. For simplicity we assume only insiders receive this type of income. In particular:

$$
\begin{aligned}
e_{I} & =k_{I} x_{I} z \\
e_{U} & =0
\end{aligned}
$$

where $k_{I}$ is a constant, $x_{I}$ is a standard normal random variable uncorrelated with all other random variables in the economy and $z$ a normal random variable statistically related to $\epsilon\left(\sigma_{\epsilon z}=\operatorname{Cov}(\epsilon, z) \neq 0\right)$. Before trading, insiders also observe the realization of the random variable $x_{I}$.

Denoting by $w_{i}$ the end of period wealth of agent $i$, by $w_{0, i}$ his initial wealth, by $n_{i}$ the number of shares of the risky asset he holds after trading and by $p$ the price of the asset at time 0 , we have:

$$
\begin{aligned}
w_{I} & =w_{0, I}+k_{I} x_{I} z+n_{I}(f-p) \\
w_{U} & =w_{0, U}+n_{U}(f-p)
\end{aligned}
$$

Agents maximize the expected utility of their end of period consumption (wealth) and behave competitively. In particular, each agent has a utility function $U_{i}: \Re \rightarrow \Re$, which exhibits constant absolute risk aversion:

$$
U_{i}\left(w_{i}\right)=-\exp \left\{-a_{i} w_{i}\right\}
$$

Before the market for assets trading opens, agents receive their private information. Insiders are in possession of two important pieces of information, $y$ and $x_{I}$. The first

\footnotetext{
${ }^{8}$ Throughout this whole section 2 we denote insiders by $I$, uninformed traders by $U$, and generic traders by $i$.
} 
one, $y$, is relevant for assessing the true value of the asset in the future; the second, $x_{I}$, is a key determinant of the size of the agents' hedging needs. In our model we allow the insiders to trade one both sources of information ${ }^{9}$. Since uninformed traders do not hold any private information, the vector $s(\omega)=\left(y, x_{I}\right) \in \Sigma \subseteq \Re^{m}$ contains all private information of the economy in state $\omega$. Endowed with their private information, agents trade in a Rational Expectations Equilibrium $(R E E)^{10}$. In this equilibrium agents use both their private information and the information contained in equilibrium prices, $p \in$ $\Re$, in the determination of their optimal asset holdings.

Definition 1 A REE $i$ s an equilibrium price function $p(s)$ and a set of optimal demand functions for insiders and uninformed traders $\left\{n_{I}\left(y, x_{I}, p\right), n_{U}(p)\right\}$ such that:

1) (measurability) $p: \Sigma \longrightarrow \Re$ is a (Borel) measurable function.

2) (optimality) $n_{I}\left(y, x_{I}, p\right)$ and $n_{U}(p)$ satisfy:

$$
\begin{aligned}
n_{I}\left(y, x_{I}, p\right) & =\operatorname{ArgMaxE}\left[U_{I}\left(w_{I}\right) \text { s.t. }(2.1) \mid y, x_{I}, p\right] \\
n_{U}(p) & =\operatorname{ArgMaxE}\left[U_{U}\left(w_{U}\right) \text { s.t. }(2.2) \mid p\right]
\end{aligned}
$$

3) (clearing) $\lambda_{I} n_{I}\left(y, x_{I}, p\right)+\left(1-\lambda_{I}\right) n_{U}(p)=\bar{n}$

For simplicity and without any bearing on the main results, we further assume that with the exception of $\sigma_{\epsilon z}$, all covariances and expectations of random variables are equal to 0 . Furthermore, all variances, except $\sigma_{\epsilon}^{2}$, are set equal to 1 . To summarize, the distributional assumptions on all the random variables are:

$$
\left(\begin{array}{l}
y \\
\epsilon \\
z \\
x_{I}
\end{array}\right) \longrightarrow \aleph\left\{\left(\begin{array}{l}
0 \\
0 \\
0 \\
0
\end{array}\right),\left(\begin{array}{cccc}
1 & 0 & 0 & 0 \\
0 & \sigma_{\epsilon}^{2} & \sigma_{\epsilon z} & 0 \\
0 & \sigma_{\epsilon z} & 1 & 0 \\
0 & 0 & 0 & 1
\end{array}\right)\right\}
$$

In section 2.3 we show that when insiders face trading constraints the REE price in

\footnotetext{
${ }^{9}$ In most countries some of the trading due to $y$ is not allowed, but trading due to $x_{I}$ is permitted. In the US, all trading on $y$ based on the the so-called "material" information is not permitted and any trade done by insiders must be reported to the SEC.

${ }^{10}$ See Radner (1979)
} 
this economy exhibit crashes. Before that, and for illustrative purposes, we compute the REE in the economy without trading constraints.

\subsection{Equilibrium in the Economy without Trading Constraints}

In the absence of trading constraints each agent solves a typical mean variance portfolio selection problem. Conditional on his information, the representative insider's future wealth is normally distributed. Taking the first order conditions, we find that his demand for the risky asset is given by:

$$
n_{I}\left(y, x_{I}, p\right)=\frac{E\left(f \mid y, x_{I}, p\right)-p-\operatorname{Cov}\left(f, e_{I} \mid y, x_{I}, p\right)}{a_{I} \operatorname{Var}\left(f \mid y, x_{I}, p\right)}=\frac{\bar{f}+y-p-a_{I} k_{I} \sigma_{\epsilon z} x_{I}}{a_{I} \sigma_{\epsilon}^{2}}
$$

The equation above implies that equilibrium prices must reveal (to the uninformed traders) $\theta\left(y, x_{I}\right) \equiv y-a_{I} k_{I} \sigma_{\epsilon z} x_{I}$, which is normally distributed. Hence, the demand function of the representative uninformed trader is identical to that of an agent with private signal $\theta\left(y, x_{I}\right)$. Thus, conditional on his signal and on the inferred information, each uninformed trader' future wealth is also normally distributed and his demand is given by:

$$
n_{U}(p)=n_{U}(\theta)=\frac{E(f \mid \theta)-p-\operatorname{Cov}\left(f, e_{2} \mid \theta\right)}{a_{U} \operatorname{Var}(f \mid \theta)}=\frac{\theta\left(y, x_{I}\right)+\left(1+m^{2}\right)(\bar{f}-p)}{a_{U}\left[m^{2}+\left(1+m^{2}\right) \sigma_{\epsilon}^{2}\right]}
$$

where $m \equiv a_{I} k_{I} \sigma_{\epsilon z}$.

The REE price is given by:

$$
\begin{gathered}
P\left(y, x_{I}\right)=K_{0}+K_{1} \theta\left(y, x_{I}\right) \\
K_{0} \equiv \bar{f}-\frac{\left[\left(1+m^{2}\right) \sigma_{\epsilon}^{2}+m^{2}\right] \sigma_{\epsilon}^{2}}{\gamma \sigma_{\epsilon}^{2}\left(1+m^{2}\right)+\frac{\lambda_{I}}{a_{I}} m^{2}} \bar{n} \\
K_{1} \equiv \frac{\gamma \sigma_{\epsilon}^{2}+\frac{\lambda_{I}}{a_{I}} m^{2}\left(1+\sigma_{\epsilon}^{2}\right)}{\gamma \sigma_{\epsilon}^{2}\left(1+m^{2}\right)+\frac{\lambda_{I}}{a_{I}} m^{2}}
\end{gathered}
$$

where $\gamma \equiv \frac{\lambda_{I}}{a_{I}}+\frac{\left(1-\lambda_{I}\right)}{a_{U}}$.

The equilibrium price is only partially revealing as it does not reveal $y$ to the uninformed traders but only a linear combination of $y$ and $x_{I}$, the endowment shock of insiders. 
At equilibrium, agents' asset holdings are given by:

$$
\begin{aligned}
& n_{I}=\frac{1}{a_{I}}\left(\frac{\left(\frac{1-\lambda_{I}}{a_{U}}\right) m^{2} \theta+\left(\left(1+m^{2}\right) \sigma_{\epsilon}^{2}+m^{2}\right) \bar{n}}{\gamma \sigma_{\epsilon}^{2}\left(1+m^{2}\right)+\frac{\lambda_{I}}{a_{I}} m^{2}}\right) \\
& n_{U}=\frac{1}{a_{U}}\left(\frac{\sigma_{\epsilon}^{2}\left(1+m^{2}\right) \bar{n}-\frac{\lambda_{I}}{a_{I}} m^{2} \theta}{\gamma \sigma_{\epsilon}^{2}\left(1+m^{2}\right)+\frac{\lambda_{I}}{a_{I}} m^{2}}\right)
\end{aligned}
$$

\subsection{Equilibrium in the Economy with Trading Constraints}

We now assume that the stock holdings of all agents, both insiders and uninformed traders, must satisfy the following portfolio constraint:

$$
\begin{gathered}
n_{I} \geq \nu \\
n_{U} \geq \nu
\end{gathered}
$$

where $\nu$ is a constant strictly smaller than $\bar{n}^{11}$.

We can decompose any equilibrium of the economy with portfolio constraints into four regions:

- Region $A$ where the signal received by the insiders is so good, or their hedging motive so strong, that they purchase all the shares that the uninformed traders can sell without violating the portfolio constraint. In that region, the portfolio constraint of the uninformed traders is binding, the portfolio constraint of the insider is not binding, and prices reveal $\theta$ to the market.

- Region $B$ where the signal received by the insiders is good enough, or their hedging motive strong enough, that they demand a larger number of shares than their minimum holding allowed but not so good or so strong as to push the uninformed traders out of the market. In that region, neither the portfolio constraint of the insiders nor the portfolio constraint of the uninformed traders are binding, and prices reveal $\theta$ to the market.

\footnotetext{
${ }^{11}$ The case $\nu=0$ corresponds to the standard no short-sales constraint.
} 
- Region $C$ where the signal received by the insiders is bad enough, or their hedging motive weak enough, that they would want to hold a number of shares below their minimum holding allowed but not so bad or so weak as to cause a crash. In that region, the portfolio constraint of the insider is binding, the portfolio constraint of the uninformed trader is not binding, and prices reveal $\theta$ to the market.

- Region $D$ where the signal received by the insiders is so bad, or their hedging motive so weak that not only insiders would want to hold a number of shares below their minimum holding allowed but also a crash (i.e. a price discontinuity) occurs. In that region, the portfolio constraint of the insider is binding, the portfolio constraint of the uninformed trader is not binding, and prices do not reveal $\theta$ to the market. Expected returns are higher in Region D than in either of the other three regions.

More formally, we show in the Appendix the following result:

Theorem 1 Let:

- $\bar{\theta} \equiv \frac{a_{I}}{\lambda_{I} m^{2}}\left(\left(1+m^{2}\right) \sigma_{\epsilon}^{2} \bar{n}-a_{U} \nu\left(\gamma\left(1+m^{2}\right) \sigma_{\epsilon}^{2}+\frac{\lambda_{I} m^{2}}{a_{I}}\right)\right)$

- $\underline{\theta} \equiv \frac{a_{U}}{\left(1-\lambda_{I}\right) m^{2}}\left(-\left(\left(1+m^{2}\right) \sigma_{\epsilon}^{2}+m^{2}\right) \bar{n}+a_{I} \nu\left(\gamma\left(1+m^{2}\right) \sigma_{\epsilon}^{2}+\frac{\lambda_{I} m^{2}}{a_{I}}\right)\right)$

- $\theta^{*}$ defined as a real number no larger than the smallest root $t^{*}$ of the equation:

$$
t+\frac{1}{\sqrt{1+m^{2}}} \frac{f\left(\frac{t+a_{U} \frac{\bar{n}-\lambda_{I} \nu}{1-\lambda_{I}}}{\sqrt{1+m^{2}}}\right)}{F\left(\frac{t+a_{U} \frac{\bar{n}-\lambda_{I} \nu}{1-\lambda_{I}}}{\sqrt{1+m^{2}}}\right)}+a_{U}\left(1+\sigma_{\epsilon}^{2}\right) \frac{\bar{n}-\lambda_{I} \nu}{1-\lambda_{I}}=\nu a_{I} \sigma_{\epsilon}^{2}
$$

where $f($.$) and F($.$) are respectively the density and the CDF of the standard normal$ distribution. There exists a continuum of rational expectations equilibria to the economy with portfolio constraints, which are characterized as follows:

i) Region $A: \forall \theta$ s.t. $\theta \geq \bar{\theta}$

$$
\text { Prices: } p_{a}(\theta)=\bar{f}+\theta-\frac{a_{I} \sigma_{\epsilon}^{2}}{\lambda_{I}}\left(\bar{n}-\left(1-\lambda_{I}\right) \nu\right)
$$


Holdings: $n_{I}=\frac{\bar{n}-\left(1-\lambda_{I}\right) \nu}{\lambda_{I}} ; n_{U}=\nu$

ii) Region B: $\forall \theta$ s.t. $\bar{\theta}>\theta \geq \underline{\theta}$

Prices: $p_{b}(\theta)=\bar{f}+\theta \frac{\gamma \sigma_{\epsilon}^{2}+\frac{\lambda_{I} m^{2}}{a_{I}}\left(1+\sigma_{\epsilon}^{2}\right)}{\gamma\left(1+m^{2}\right) \sigma_{\epsilon}^{2}+\frac{\lambda_{I} m^{2}}{a_{I}}}-\bar{n} \frac{\sigma_{\epsilon}^{2}\left(\left(1+m^{2}\right) \sigma_{\epsilon}^{2}+m^{2}\right)}{\gamma\left(1+m^{2}\right) \sigma_{\epsilon}^{2}+\frac{\lambda_{I} m^{2}}{a_{I}}}$

Holdings: $n_{I}=\frac{1}{a_{I}}\left(\frac{\left(\frac{1-\lambda_{I}}{a_{U}}\right) m^{2} \theta+\left(\left(1+m^{2}\right) \sigma_{\epsilon}^{2}+m^{2}\right) \bar{n}}{\gamma \sigma_{\epsilon}^{2}\left(1+m^{2}\right)+\frac{\lambda_{I}}{a_{I}} m^{2}}\right) ; n_{U}=\frac{1}{a_{U}}\left(\frac{\sigma_{\epsilon}^{2}\left(1+m^{2}\right) \bar{n}-\frac{\lambda_{I}}{a_{I}} m^{2} \theta}{\gamma \sigma_{\epsilon}^{2}\left(1+m^{2}\right)+\frac{\lambda_{I}}{a_{I}} m^{2}}\right)$

iii) Region $C: \forall \theta$ s.t. $\underline{\theta}>\theta \geq \theta^{*}$

Prices: $p_{c}(\theta)=\bar{f}+\frac{\theta}{1+m^{2}}+\frac{\left(1+m^{2}\right) \sigma_{\epsilon}^{2}+m^{2}}{\left(1-\lambda_{I}\right)\left(1+m^{2}\right)}\left(\lambda_{I} a_{U} \nu-a_{U} \bar{n}\right)$

Holdings: $n_{I}=\nu ; n_{U}=\frac{\bar{n}-\lambda_{I} \nu}{1-\lambda_{I}}$

iv) Region D: $\forall \theta$ s.t. $\theta<\theta^{*}$,

Prices: $p_{d}(\theta)=p^{*} \equiv \bar{f}-\frac{1}{\sqrt{1+m^{2}}} \frac{f\left(\frac{\theta^{*}+a_{U} U \frac{\bar{n}-\lambda_{I} \nu}{1-\lambda_{I}}}{\sqrt{1+m^{2}}}\right)}{F\left(\frac{\theta^{*}+a_{U} \frac{\bar{n}-\lambda_{I} \nu}{1-\lambda_{I}}}{\sqrt{1+m^{2}}}\right)}-a_{U}\left(1+\sigma_{\epsilon}^{2}\right) \frac{\bar{n}-\lambda_{I} \nu}{1-\lambda_{I}}<p_{c}\left(\theta^{*}\right)$

Holdings: $n_{I}=\nu ; n_{U}=\frac{\bar{n}-\lambda_{I} \nu}{1-\lambda_{I}}$.

\section{Proof: (See Appendix)}

In this economy equilibrium holdings are determined but equilibrium prices are indeterminate (multiplicity of equilibria). A typical equilibrium is illustrated in Figure 2. The key features of any equilibrium of the economy with trading constraints are the following:

1. Prices are discontinuous at the point $\theta=\theta^{*}$. In other words, a crash occurs between Regions C and D.

2. Insiders holdings are constant in Region C. This means that a crash is preceded by a region where insiders do not trade.

3. The trading constraint of insiders is binding in Regions C and D. In other words, for a crash to occur insiders need to have divested in the stock.

4. Prices are continuous at the point $\theta=\bar{\theta}$. In other words, a jump does not occur when the trading constraint of uninformed investors is binding and insiders have purchased the maximum amount of stock possible.

[Insert figure 2] 


\section{EMPIRICAL STUDY}

In this section, we document a systematic pattern of insider trading preceding large drops in stock prices which is consistent with the qualitative properties of the model in Section 2. We test our model against competing stories such as patterns of insider trading driven by earnings announcement dates, or insiders timing their trades to evade prosecution. We argue that our results invalidate the mainstream view that insider sales are solely driven by liquidity needs. Finally we provide new evidence regarding crashes and the degree of information asymmetry.

\subsection{Data, Variable Definitions and Methodology}

\subsubsection{The Data}

Our tests require merging data from two different sources. The Thomson Financial Insider Filings (TFIF) database collects all insider trades reported to the $\mathrm{SEC}^{12}$. The CRSP database provides data on returns, total trading volume and market capitalization. We use this data to identify crashes at the firm level. Our universe of securities includes all common stocks (with CRSP share code equal to 10 or 11) that trade on the NYSE, AMEX, and Nasdaq markets from January 1985 to December $2002^{13}$. The procedures for selecting firms and cleaning the data are taken directly from Lakonishok and Lee (2001).

Starting with the CRSP data, we exclude observations (firm/month record) for which we do not have the monthly returns. We also exclude stocks that had a price smaller than $\$ 2$ at the beginning of the calendar year in order to avoid the measurement errors described in Conrad and Kaul (1993).

\footnotetext{
${ }^{12}$ According to Section 16(a) of the Securities and Exchange Act, insiders are required to report their trades by the tenth day of the month that follows the trading month. Reporting requirements have tightened recently as the Sarabanes-Oxley Act of 2002 requires reporting to the SEC within two business days following the insider's transaction date.

${ }^{13}$ In addition to CRSP and TFIF, we use the COMPUSTAT database for two sets of regressions in subsection 4.4, where earnings announcement data is necessary for testing our model against an alternative hypothesis.
} 
The TFIF database comprises transactions done by three groups of insiders ${ }^{14}$ : "Management", "Large Shareholders" and "Others". Our sample contains transactions done between 1986 and $2002^{15}$. We eliminate filings that do not match with CRSP data. This can happen because the security does not appear in the CRSP dataset or because it is a non-common share. From the remaining filings, 889,473 correspond to open market or private sales (transaction code S), and 490,882 to open market or private purchases (transaction code $\mathrm{P}$ ). We focus on these transactions in this study as they are more likely to be at least partly driven by information. The remaining records correspond to other types of transactions, in particular grants and awards or exercise of derivatives, which we do not include in our sample. We also exclude amended records, trades for which we do not have the insiders transaction price nor the closing price of the stock, and small transactions where less than 100 shares were traded. Finally, some fillings in which the reported transaction price is not within $20 \%$ of the CRSP closing price on that day, or that involves more than the $20 \%$ of the number of shares outstanding are eliminated to avoid problematic records. After this cleansing process and after merging the insider trading dataset with the filtered CRSP dataset, our sample contains 1,183,457 records. From those, 799,890 are sales, and 383,567 are purchases, which are distributed as follows: 979,467 transactions done by "Management", 185,096 done by "Large Shareholders" and 18,894 done by "Others".

\subsubsection{Crash variables}

The first step in our empirical analysis consists in identifying crashes at the individual stock level. Both our model and the data available put a number of constraints at this

\footnotetext{
${ }^{14}$ The "Management" group includes those transactions done by the chairman, directors, CEOs, CFOs, officers, presidents, vice presidents, affiliates, members of committees, etc. The "Large Shareholders" group includes those equity-holders (direct shareholders, indirect shareholders and beneficial owners) who own more than $20 \%$ of shares and are not management. Finally, the transactions by the rest of insiders (for example, founders or former managers) are classified as "Others".

${ }^{15}$ The Lakonishok and Lee (2001) study covers the period 1975 to 1995 . So our dataset misses some of the earlier observations but focuses on the later period where insider trading has been relatively more active.
} 
stage:

1. In our model, insider trading matters because it is observable to market participants and these update their beliefs as insiders' trades, or lack of trades, are observed. In reality, prior to the Sarabanes-Oxley Act of 2002, there could exist a gap of a few days to a few weeks between the date at which the trade took place and the date at which it is reported. While one can reasonably expect that the information about the insiders' trades becomes available to market participants at some point between these two dates, it seems difficult for us to take a harder stance about the speed of revelation of information. This leads us to conduct our empirical analysis at a monthly frequency.

2. While insiders have private information about their own company, they do not necessarily have valuable information about the evolution of the entire market. Thus, if insider trading and crashes are related at the individual stock level, they must be for crashes driven by idiosyncratic shocks and not for crashes driven by market-wide corrections. Consequently, our measure of crashes at the individual stock level should correct for moves of the aggregate market.

3. Our theoretical model has sharp testable implications about the patterns of insider trading prior to a crash. However, it does not have similar implications regarding expected returns or conditional skewness ${ }^{16}$. The model does not provide restrictions about the size of the crash when a crash occurs either ${ }^{17}$. Thus, if we are to take our model seriously we must define a crash as a binary variable (either a crash occurred or it did not occur) and test whether patterns of insider trading can predict the probability of a crash.

Taking into account these restrictions, we construct our first baseline variable for a crash in stock $i$ in month $t, E R C R A S H_{i, t}$, as follows. We first compute the series of

\footnotetext{
${ }^{16}$ In particular, before a crash occurs, expected returns are the same no matter the pattern of insider trading.

${ }^{17}$ This is because of the multiplicity of equilibria in our model.
} 
monthly excess returns for each stock, $r_{i, t}^{E R} \equiv r_{i, t}-r_{m, t}$, where $r_{i, t}$ is the raw return of stock $i$ in month $t$ and $r_{m, t}$ the monthly return of the CRSP equally weighted market portfolio. Then for each observation (stock/month) we compute the mean excess return, $\bar{r}_{i, t}^{E R}$, and the standard deviation of excess returns, $\sigma_{i, t}^{E R}$, over a rolling window of the past five years, or sixty months, of data. Finally, we define:

$$
\operatorname{ERCRASH}_{i, t}= \begin{cases}1, & \text { if } r_{i, t}^{E R}-\bar{r}_{i, t}^{E R} \leq-2 \sigma_{i, t}^{E R} \\ 0, & \text { otherwise. }\end{cases}
$$

Our second baseline variable for a crash, $M M C R A S H_{i, t}$, is constructed in a similar fashion, except that excess returns are constructed by taking the difference between the stock's monthly return and its estimated return in a market model regression. That is, we define, $r_{i, t}^{M M} \equiv r_{i, t}-\left(r_{f, t}+\beta_{i, t}\left(r_{m, t}-r_{f, t}\right)\right)$, where $\beta_{i, t}$ is the beta of the stock estimated over a sixty months window and $r_{f, t}$ is the risk-free rate. We then compute the standard deviation of the residuals of the market regression, $\sigma_{i, t}^{M M}$. Finally, we formally define:

$$
M M C R A S H_{i, t}= \begin{cases}1, & \text { if } r_{i, t}^{M M}-\bar{r}_{i, t}^{M M} \leq-2 \sigma_{i, t}^{M M} \\ 0, & \text { otherwise. }\end{cases}
$$

To check the robustness of our results with respect to our definition of $\operatorname{crashes}^{18}$, we also compute another measure of crashes, $R A W C R A S H_{i, t}$, which is constructed in the same way as the other two measures of crashes but using raw returns instead of excess returns or residuals from the market model. As can be expected, the three measures of crashes are fairly close to one another. Figure 3 represents the number of crashes per year over the 15 years of our sample according to each measure. Table 1 provides the sample correlation between the three measures of crashes. As could be expected, both Table 1 and figure 3 show a strong positive correlation between our three measures of crashes, especially between ERCRASH and MMCRASH. Note also that according to all three measures, the post 1996 period has the largest number of crashes ${ }^{19}$.

\footnotetext{
${ }^{18}$ Robustness checks of the main regression are provided in subsection 3.2.3

${ }^{19}$ Another way of checking how closely related the three measures are is looking at the monthly threshold return required by the alternative definitions for a crash to happen. The median of this threshold in our sample is $-21.58 \%,-23.03 \%$ and $-21.78 \%$, for $r_{i, t}^{E R}, r_{i, t}^{M M}$ and $r_{i, t}$, respectively.
} 
[Insert table 1]

[Insert figure 3]

Finally, as we want to compare patterns of insider trading prior to crashes to patterns of insider trading prior to jumps, where by "jump" we mean a large positive price movement, we construct the variables ERJUMP $P_{i, t}, M M J U M P_{i, t}, R A W J U M P_{i, t}$. Each of these four variables is defined in a totally symmetric fashion as their crash variables counterparts. For instance, we have:

$$
\text { ERJUMP } P_{i, t}= \begin{cases}1, & \text { if } r_{i, t}^{E R}-\bar{r}_{i, t}^{E R} \geq 2 \sigma_{i, t}^{E R} \\ 0, & \text { otherwise. }\end{cases}
$$

Figure 4 represents the number of jumps per year according to each measure and Table 2 provides the sample correlation between these three measures of jumps. We observe that our three measures of jumps are even more strongly and positively correlated with one another than in the case of crashes. We also observe a sharp increase in the number of jumps after 1996.

[Insert table 2]

[Insert figure 4]

\subsubsection{Independent variables}

Independent variables fall in two categories: variables suggested by our model and variables suggested by the existing literature. Variables suggested by our model mostly consist in different measures of insider trading. In our empirical study, insider trading includes all private or public market purchases and sales done by all categories of insiders. We do not include grants and exercises of options as they are less likely to be driven by information. To homogenize the insider trading variables across stocks and across time, we normalize them by dividing the dollar value of each particular trade by the market capitalization of the stock, computed using the closing price of the day of the transaction. The main variables we use are: insider sales, INSSAL, and insider purchases, INSPURCH. A first subscript, $i$, refers to the individual stock considered. The variable may then have one or two time subscripts. If there is 
only one time subscript, then the variable refers to trades that took place during the corresponding month $t$. Thus $I N S S A L_{i, t}$ gives the total amount of insider sales on stock $i$ during month $t$. If there are two time subscripts, then the variable refers to the monthly average between the two time subscripts. Thus INSPURCH $H_{i, t-1, t-12}$ gives the average monthly amount of insider purchases on stock $i$ between month $t-1$ and month $t-12$. In addition to these two basic categories of variables, we define composite variables such as insider trading volume, INSTV, which is defined as insider sales plus insider purchases.

Table 3 provides summary statistics on aggregate insider trading activity in our sample. Figure 5 represents the evolution of insider purchases and sales over time. An important point to note from figure 5 is that insider transactions, and most notably insider sales, have been much larger in the 90's than in the 80's. This observation suggests that findings regarding correlations between insider activity and crashes may be sensitive to the choice of sub-sample. In subsection 3.2.3 we address this issue.

[Insert table 3]

[Insert figure 5]

Independent variables suggested by the existing literature include trading volume and past returns. First, Chen et al. (2001) have shown that total trading volume (i.e. both by insiders and outsiders), which we thereafter note as $T T V$, is a strong predictor of negative skewness, a concept very much related to crashes. Their interpretation of the results, consistent with the Hong and Stein (2003) model, is that TTV acts as a proxy for the dispersion of opinions across investors. When interpreting our own results we want to make sure that trading volume by insiders does not act as a proxy for $T T V$. Thus we include $T T V$, at the same frequency as our insider trading variables, in all our regressions. Similarly, the cumulative excess return over the equally weighted market portfolio of the past two years, $E R_{t-1, t-24}$ is likely to matter for two reasons. First, Lakonishok and Lee (2001) have shown that insiders are contrarian investors. If valuable information about crashes is contained in insider trading, it is likely to be contained in the unexpected component of insider trading. Thus, to the extent that 
past returns predict insider trading, we want to include the variable in our regression. Another reason for including past returns is the finding by Chen et al. (2001) that past returns can predict negative skewness. Finally, our main regressions allow for firm and year effects ${ }^{20}$.

\subsubsection{Methodology}

The binary nature of our dependent variables raises some estimation concerns. There are three leading estimation procedures for regressions with a binary dependent variable: the linear probability model (OLS), and the logit and probit models. Each procedure has some defects: with the linear probability model, estimated probabilities may lie outside the $[0,1]$ interval and disturbances are heteroskedastic. With logit and probit, coefficients of group dummy variables cannot be estimated and the interpretation of coefficients is less straightforward than with the linear probability model.

To the extent that our objective is not as much to get an estimate of the probability of a crash as to test whether or not insider trading patterns are correlated with crashes and jumps, we use the linear probability model in our main regressions. Since we know that using the linear probability model will give rise to heteroskedasticity and since we can also suspect problems of auto-correlation, we report significance of coefficients based on Newey-West standard errors. As a robustness test, we also estimate our leading regressions using logit and probit and report the results in subsection 4.3.

\subsection{Empirical Results}

In the introduction we established a dichotomy in the literature that view crashes as a phenomenon that arises because of the existence of trading constraints. Models like Romer (1993), Cao et al. (2002) and Hong and Stein (2003) share the property that crashes occur when previously sidelined informed investors get back into the market. Our model, like Gennotte and Leland (1990), Barlevy and Veronesi (2003) and by Yuan

\footnotetext{
${ }^{20}$ An example of firm's characteristics that may have an impact on crashes is size as suggested by Chen et al. (2001)
} 
(2005), has the opposite property: crashes occur when informed investors get out of the market. Before testing specific implications of our model, we want to check more generally whether the data favors or not the type of models ours belongs to. Despite the wealth of theoretical models on crashes there has been so far, to the best of our knowledge, no attempt has been made to ask the data the simple question: Do informed investors get into or out of the market before a crash?

\subsubsection{Preliminary result: Sidelined investors vs. the dog that did not bark}

To answer the previous question we run regressions of our two baseline measures of crashes, ERCRASH $H_{i, t}$ and $M M C R A S H_{i, t}$ against insiders trading volume as the measure of insider trading activity. In particular we regress our measures of crashes on the past month trading volume by insiders $I N S T V_{i, t-1}$ and the average monthly insiders trading volume in the past year, excluding the last $\operatorname{month}^{21}, I N S T V_{i, t-2, t-12}$. We also include the past two years cumulative excess returns $E R_{i, t-1, t-24}$ and the total trading volume (by both insiders and outsiders) of the past month $T T V_{i, t-1}$. Fixed month and firms effects are allowed for through mean-differencing.

Table 4 presents the results of these first two regressions. Column 1 presents the results for $E R C R A S H_{i, t}$ and column 2 for $M M C R A S H_{i, t}$. The results are conclusive on the relationship between crashes and insiders activity: there is a negative and significant (at the $1 \%$ level) correlation between current insiders trading volume and the probability of a crash. Furthermore crashes are positively correlated with far past trading volume (although the coefficient is not significant in the case of crashes according to the $M M C R A S H$ definition). Our empirical result is clear in its task of sorting among theories of crashes in the presence of trading constraints. It establishes that a crash is more likely to occur when insiders are getting out of the market than when they are getting back into the market. If any, increased insiders trading activity is associated with crashes in the far future. The result thus supports the general class of

\footnotetext{
${ }^{21}$ The choice of a one year window is arbitrary. However, results based on a different choice of horizon are qualitatively similar to the ones presented here.
} 
theories of crashes our model belongs to.

[Insert table 4]

Finally, the variables $E R_{i, t-1, t-24}$ and $T T V_{i, t-1}$ are also strongly significant and of the same sign as found in the existing literature, most notably Chen et al. (2001). The fact that $I N S T V_{i, t-1}$ is negatively correlated with the probability of a crash when controlling for the previous two variables is also relevant as it dispels any suspicion that our insider trading variables may play the role of a proxy for total trading volume. Indeed, insider trading volume over the past month is negatively correlated with the probability of a crash while total trading volume is positively correlated, and in both cases the coefficients are significant at the $1 \%$ level.

\subsubsection{Baseline regression: insider sales and crashes}

In this section we directly test the empirical implications of our theory of asset crashes. The main implication of the model in section 2 is that a crash occurs in a region characterized by insiders being short-sale constrained. In order for insiders to be shortsale constrained they must have sold shares in the past. So, the main prediction of the model is that nearby sales by insiders must be negatively correlated with the probability of a crash while far away sales must be positively correlated.

To test this hypothesis we regress our measures of crashes, ERCRASH $H_{i, t}$ and $M M C R A S H_{i, t}$, against sales by insiders in the past month $I N S S A L_{i, t-1}$ and the average sales by insiders in the past year, $I N S S A L_{i, t-2, t-12}$. We also include the past two years cumulative excess returns $E R_{i, t-1, t-24}$ and the total trading volume (by both insiders and outsiders) of the past month $T T V_{i, t-1}$. Fixed year and firms effects are allowed for through mean-differencing. Formulating regressions in this fashion presents three advantages:

1. Our model still has predictions for the sign of the coefficients. On the one hand, the sign of $I N S S A L_{i, t-2, t-12}$ should be positive since, ceteris paribus, more sales by insiders in the past bring them closer to the point where the constraint is binding and increases the probability of a crash. On the other hand, the sign of 
INSSAL $L_{i, t-1}$ should be negative since a crash is supposed to occur after insiders have stopped trading.

2. The alternate hypothesis provided by a standard static efficient market model without constraints can also be tested. The coefficient of $I N S S A L_{i, t-2, t-12}$ should not be significant since it is a variable which was public information by month $t-1$ (taking the most conservative stance about when the trades were reported by insiders and the diffusion of information). The coefficient of INSSAL $L_{i, t-1}$ should either be non significant or positive, again depending on the speed of reporting and of diffusion of information.

3. These regressions allow us to test whether the market believes that valuable information is contained in insider sales. Indeed, if it were not the case, as suggested by the existing literature on insider trading, then none of the coefficients of the insider sales variables should come up significant.

Table 5 contains the results of the regression of crashes on sales. In the first column crashes are defined using excess returns over the market portfolio; in the second column crashes are computed using residuals from the market model. For both regressions, coefficients of the insider sales variables are statistically significant. As argued above, this finding is in very sharp contrast with the conclusion of the existing literature on insider trading that insider sales are mostly driven by liquidity. Second, we find that the signs of each coefficient correspond to the predictions of our model and do not correspond to the predictions of a "standard" efficient market model: the sign of $I N S S A L_{i, t-1}$ is negative, which can only be reconciled with a "standard" efficient market model if insiders were selling when the risk of a crash is lowest while it is fully consistent with our "Dog that did not bark" theory. Similarly, the sign of the $I N S S A L_{i, t-2, t-12}$ variable is positive which is consistent with our interpretation that crashes occur when insiders' holding get close to the point where their short-selling constraint is binding.

[Insert table 5] 
The strong statistical significance of the insiders sales variable is in sharp contrast with an important literature that has argued that insiders purchases, rather than sales, are the only insiders' transactions with an informational content and the source of profitable trading rules. Lakonishok and Lee (2001) examines insider trading activity of companies traded on the NYSE, AMEX and NASDAQ during the 1975-1995 period. After controlling for size, book to market and momentum effects, they find a statistically and economically significant excess return of $4.82 \%$ for portfolios of stocks with a strong "purchase signal" but at the same time find a positive but statistically nonsignificant coefficient for strong "sell signals". Jeng et al. (2003) estimate the returns to the insiders' own portfolio over a six-month window. They construct a "purchase portfolio" that holds all shares purchased by insiders over a six month period and a "sale portfolio" that holds all shares sold by insiders over a six month period. They find that the purchase portfolio earns positive abnormal returns of the order of 50 basis points per month while the sale portfolio earns no negative abnormal return. Friederich et al. (2002) and Fidrmuc et al. (2004) provide evidence based on UK data suggestive of significantly smaller absolute price reaction to insider sales than to insider purchases. Thus, the consensus of the existing literature is that "insider selling that is motivated by private information is dominated by portfolio rebalancing for diversification purposes" (Lakonishok and Lee (2001).

The empirical evidence reported in table 5 is consistent with a few other possible explanations, apart from our model. One possible explanation is the fact that insiders are unlikely to trade on sensitive short-lived information. This is because insiders trading on information want to escape scrutiny from the SEC and the SEC is likely to investigate any trade by insiders that took place a few days before a crash. The absence of trading on short-lived information could also arise because of the "short swing" rule of the 1934 Security Exchange Act that prohibits profit-taking by insiders for offsetting trades within six months. A second possible explanation has to do with earning announcements. Indeed, many large drops in prices are due to companies failing to meet earnings expectations and we know that most companies prohibit insiders from 
trading prior to an earning announcement. Thus, our finding that crashes are preceded by a drop in selling by insiders could potentially be a pure artefact driven by calendar effects.

We shall go back to the earnings announcement explanation in subsection 4.4 where we test it explicitly against our model. However, testing the "no trading on shortlived information" story against our model can easily be done at this stage. Indeed, another implication of our model is that while continuous sales by insiders followed by a period of no selling may drive a crash because of the short-sale constraint, continuous purchases followed by a period of no buying will not drive a jump. Indeed, the absence of a "ceiling" constraint explains that there is no jump in Region A. Thus, we should not expect insider purchases to become significant if we run the symmetric regressions for jumps. By way of contrast, the "no trading on short-lived information" story is perfectly symmetric: whether it is for avoiding prosecution by the SEC or because of the six months short swing rule, traders should abstain from trading on short-live positive information the same way as they do with negative information.

In table 6 we present the results of regressions where we run $E R J U M P_{i, t}$ and $M M J U M P_{i, t}$ against the past month purchases by insiders INSPURCH $H_{i, t-1}$ and the average purchases by insiders in the past year INSPURCH $H_{i, t-2, t-12}$ (excluding the last month's). As before, we include the past two years cumulative excess returns $E R_{i, t-1, t-24}$, total trading volume (by both insiders and outsiders) of the past month $T T V_{i, t-1}$ as well as year and firm dummies. We observe that the results of the jump regressions are consistent both with our model and with the predictions of a standard efficient market hypothesis: the coefficient of INSPURCH $H_{i, t-2, t-12}$ is statistically insignificant while the coefficient INSPURCH $H_{i, t-1}$ is positive and significant ${ }^{22}$. They are however inconsistent with any of the alternate explanations of the crash regressions. The main message of this section is that any theoretical model trying to explain the patterns of insider trading prior to crashes also has to come to grip with the absence

\footnotetext{
${ }^{22}$ The lack of significance of the coefficient associated with INSPURCH $H_{i, t-2, t-12}$ is not driven by multicolinearity considerations as the correlation between INSPURCH $H_{i, t-2, t-12}$ and INSPURCH $H_{i, t-1}$ is just 0.01 .
} 
of similar patterns prior to jumps.

[Insert table 6]

\subsubsection{Robustness Checks}

We now proceed to check the robustness of our base regressions. We want to check the robustness of our results with respect to sample period, estimation technique and definition of the variables, both dependant and independent.

As mentioned in Subsection 3.1.3, and illustrated in Figure 5, insider trading, as a fraction of market capitalization, has increased sharply in the mid 90's. This opens up the question of how robust our results are to the choice of sample period. We split our sample into two sub-samples, one covering the period 1986-1995 (low insider trading) and the other the period 1996-2002 (high insider trading) and run the base regressions on the two separate sub-samples. Table 7 reports the results for the leading regressions for each subperiod. As could be expected given the relative activities of insider trading in the two periods, results for the earlier period are less strong than for the later period. Nevertheless, results are supportive of our theory. For the 1986-1995 period, all insider trading variables in the crash regressions are of the right sign predicted by the theory even though, to one exception, they lose significance. Also, the asymmetry between crashes and jumps is preserved: high insider sales in the previous month lower the probability of a crash while high insider purchases raise the probability of a jump. As expected, results for the 1996-2002 period are strongly supportive of our theory: all insider trading variables are of the right sign and significant at the $1 \%$ level (to one exception, which is only significant at the $5 \%$ level).

[Insert table 7]

Our next sequence of checks deals with the estimation technique. For simplicity and ease of interpretation, we estimated the base regressions using a linear probability model. In Tables 8 and 9 we report results of similar regressions using, respectively, a logit and a probit model ${ }^{23}$ to specify the probability of a crash. The results of

\footnotetext{
${ }^{23}$ Both sets of regressions include year dummy variables whose coefficients are not reported in the
} 
the regressions are quite encouraging. When crashes are defined using simple excess returns, all insider trading variables are of the right sign and significant, both with the logit and with the probit specifications. Also, as in all our regressions, the asymmetry between crashes and jumps is preserved. When crashes are defined using a market model, results are less strong. The good news for our theory is that the "dog that did not bark" effect remains significant: under both specifications, higher insider sales in month $t-1$ lowers the probability of a crash in month $t$. Also, the asymmetry between crashes and jumps is again preserved. However, the "long term" insider sales variables becomes totally insignificant (and of the wrong sign)

[Insert table 8]

[Insert table 9]

Our final robustness check concern the way we constructed our crash variables as well as our insider trading variables. We first check if the 1-year window for insiders activities preceding large price movements is critical for the results. In table 10 we report the regression results for two alternative windows: six months and 24 months. In these regressions the near past variable remains as in the baseline regression (one month), but the far past variables goes back to months $t-6$ and $t-24$. The results are at least as strong as the ones in the baseline regressions: the coefficients have the right sign and (to one exception) are very strongly significant. The "dog that did not bark" effect is present for crashes and absent for jumps, as predicted by the theory.

[Insert table 10]

Finally, in table 11 we report the results of the base regressions but using a definition of crashes and jumps based on raw returns, rather than returns in excess of the CRSP equally weighted market portfolio or the returns predicted by the market model. To the extent that our model is not a model of market-wide crashes, we expected the results of this regression to be considerably noisier than when adjustments for market changes are being made. The results are consistent with our expectations: the "long-term" insider trading variable remains of the right sign and significant at the $1 \%$ level but tables. 
the "short-term" variable is insignificant (and of the wrong sign).

[Insert table 11]

The overall picture we draw from these robustness tests is that the effects we identified in the previous section seem to be quite robust. In most of the alternate specifications we tried, both insider trading variables remained of the right sign and significant for the crash regressions. In some regressions, one of the variables stopped being significant but never two at the same time, nor did we observe a coefficient coming with the wrong sign and even mildly significant. Finally, the asymmetry between crash and jump regressions, which we argued earlier is one of our most striking findings remains present in all alternate specifications.

\subsubsection{Crashes and Earning Announcements}

The last item we have so far left aside concerns the alternative interpretation of our results based on the possible coincidence of crash dates and earnings announcement dates. According to that hypothesis, there may be a large proportion of crashes that take place during months where an earning announcement takes place, because of the company's earnings failing to meet the market's expectations. To the extent that insiders are prevented from trading their own company's stock for a few weeks prior to the earning announcement, it is natural to see crashes associated with low trading by insiders the previous month. Thus, if the alternate hypothesis is correct, the correlation between crashes and insider trading is a pure artefact driven by calendar effects, and the absence of trading by insiders contains no valuable information for outsiders.

In order to test our hypothesis against this alternative hypothesis, we merge our data set with information from COMPUSTAT regarding earnings announcements. We eliminate all observations for which we do not have data regarding earnings announcement dates for that stock and that year. We then construct a sub-sample with only observations (stock/month) where no earning announcement was made for that stock during that month. We then run the base regressions for that sub-sample.

The results, reported in Table 12, are unambiguous: all coefficients of insider trading 
variables for the crash regressions are significant at the $1 \%$ or at the $5 \%$ level and of the right sign predicted by the theory. By way of contrast, none of the insider trading variables are significant for the jump regressions, which confirms our earlier findings of the crash/jump asymmetry.

[Insert table 12]

To further confirm the interpretation of our results, we perform one last test: we run the base regressions on the sub-sample where all observations correspond to a month where an earning announcement took place. To the extent that insider trading is strongly regulated for most firms around these periods, both in terms of purchases and of sales, uninformed traders should not be able to draw any inference, either positive or negative, from the pattern of insider trading around those dates. Thus, if our theory that the pattern of insider trading around crashes is driven by informational considerations is correct, then insider trading variables should stop being significant in the sub-sample. The results we report in table 13 support that hypothesis: not only insider sales the month before stop being significant, which is expected given that there is very little insider trading around earning announcement dates, but average insider sales of the previous year stop being significant as well.

[Insert table 13]

\section{CONCLUDING REMARKS}

Insider trading and crashes in asset prices are among the finance concepts that have historically attracted the largest amount of attention, both in the academic arena and among practitioners. In this paper we introduce a theoretical framework that relates them in a novel fashion. The model we develop in this framework points at a clear pattern of insiders selling intensity preceding crashes (high in the far past and low in the near past) with no symmetric counterpart in the case of insiders purchases and jumps. Our empirical study shows that the evidence in the US markets is consistent with all the model predictions. These results highlight an informative role of insiders sales completely ignored in the literature. 
We believe this paper sets the starting point in a new way of thinking about insider trading and crashes. As such, it leaves many questions unanswered and open lines for further research. First, it would be interesting to see if equity or options portfolios based on the sequence of insider sales our model suggests exhibit abnormal performance. It would also be interesting to perform a more disaggregate analysis sorting our sample according to firm characteristics (such as size) that we think are correlated with the intensity of the diversification motive for insider sales in each of the firms. This would allow us to concentrate in a specific segment of the market in which ex-ante we should expect our results to be stronger (weaker) because of a smaller (larger) noise introduced by noninformationally driven insider sales. Finally, from an international perspective, it would be interesting performing the same tests performed here across countries with different insider trading regulations.

\section{References}

Allen, F. and Gale, D. (2000). Bubbles and crisis. The Economic Journal, 110:236-255.

Allen, F., Morris, S., and Postlewaite, A. (1993). Finite bubbles with short sale constraints and asymmetric information. Journal of Economic Theory, 61(2):206-229.

Allen, F., Morris, S., and Shin, H. (2003). Beauty contests, bubbles and iterated expectations in asset markets. Discussion Paper 1406, Cowles Foundation.

Barlevy, G. and Veronesi, P. (2003). Rational panics and stock market crashes. Journal of Economic Theory, 110(2):234-63.

Bhattacharya, U. and Spiegel, M. (1991). Insiders, outsiders and market breakdowns. The Review of Financial Studies, 4(2):255-82.

Cao, H., Coval, J., and Hirshleifer, D. (2002). Sidelined investors, trading-generated news, and security returns. The Review of Financial Studies, 15(2):615-48.

Chen, J., Hong, H., and Stein, J. (2001). Forecasting crashes: Trading volume, past 
returns, and conditional skewness in stock prices. Journal of Financial Economics, 61(3):345-81.

Conrad, J. and Kaul, G. (1993). Long-term market overreaction or biases in computed returns? The Journal of Finance, 48:39-63.

Devenou, A. and Welch, I. (1996). Rational herding in financial economics. European Economic Review, 40(3-5):603-15).

Fidrmuc, J., Goergen, M., and Renneboog, L. (2004). Director share dealings and corporate control. Mimeo, Tilburg University.

Friederich, S., Gregory, A., Matatko, J., and Tonks, I. (2002). Short-run returns around the trades of corporate insiders on the london stock exchange. European Financial Management, 8(1):7-30.

Gennotte, G. and Leland, H. (1990). Market liquidity, hedging and crashes. American Economic Review, 80:999-1021.

Grossman, S. J. and Stiglitz, J. E. (1980). On the impossibility of informationally efficient markets. American Economic Review, 70(3):393-408.

Hong, H., Scheinkman, J., and Xiong, W. (2005). Asset float and speculative bubbles. Working Paper 11367, NBER.

Hong, H. and Stein, J. (2003). Differences of opinion, short-sales constraints, and market creshes. The Review of Financial Studies, 16(2):487-525.

Jeng, L., Metrick, A., and Zeckhauser, R. (2003). Estimating the returns to insider trading: A performance evaluation perspective. The Review of Economics and Statistics, 85(2):453-71.

Lakonishok, J. and Lee, I. (2001). Are insider trades informative? The Review of Financial Studies, 14(1):79-111. 
Marin, J. M. and Rahi, R. (2000). Information revelation and market incompleteness. The Review of Economic Studies, 67(3):563-579.

Radner, R. (1979). Rational expectations equilibrium: Generic existence and the information revealed by prices. Econometrica, 47(3):655-678.

Romer, D. (1993). Rational asset-price movements without news. American Economic Review, 83(5):1112-30.

Yuan, K. (2005). Asymmetric price movements and borrowing constraints: A rational expectations equilibrium model of crises, contagion, and confusion. The Journal of Finance, 60(1):379-411.

\section{A Appendix}

\section{A.1 Proof of Theorem 1}

Region A. From the study of the unconstrained economy, we have that the demand of the representative insider is given by:

$$
\begin{aligned}
n_{I}\left(y, x_{I}, p\right) & =\operatorname{Max}\left(\frac{\bar{f}+\theta-p}{a_{I} \sigma_{\epsilon}^{2}} ; \nu\right)=\operatorname{Max}\left(\frac{\bar{n}-\left(1-\lambda_{I}\right) \nu}{\lambda_{I}} ; \nu\right) \\
& =\frac{\bar{n}-\left(1-\lambda_{I}\right) \nu}{\lambda_{I}}
\end{aligned}
$$

since $\nu<N$.

It can easily be checked that any price $p \geqslant p(\bar{\theta})$ corresponds to one and only one $\theta$. Thus prices reveal $\theta$ in Region $A$ and, as seen in the study of the uncostrained economy, the demand of the uninformed traders is given by:

$$
\begin{aligned}
n_{U}(p) & =\operatorname{Max}\left(\frac{\left(1+m^{2}\right)(\bar{f}-p)+\theta}{a_{U}\left(\left(1+m^{2}\right) \sigma_{\epsilon}^{2}+m^{2}\right)} ; \nu\right) \\
& =\operatorname{Max}\left(\frac{-m^{2} \theta+\frac{\left(1+m^{2}\right) \sigma_{\epsilon}^{2} a_{I}}{\lambda_{I}}\left(\bar{n}-\left(1-\lambda_{I}\right) \nu\right)}{a_{U}\left(\left(1+m^{2}\right) \sigma_{\epsilon}^{2}+m^{2}\right)} ; \nu\right)=\nu \text { if } \theta \geq \bar{\theta}
\end{aligned}
$$

Thus, the market clearing condition is satisfied in Region A. 
Region B. The derivation of equilibrium prices and equilibrium holdings in this region is identical to that of the equilibrium of the economy without portfolio constraints. The restriction that equilibrium holdings need to be larger than $\nu$ for both types of agents provides the condition $\bar{\theta}>\theta \geq \underline{\theta}$

Region C. For insiders, we have as before:

$$
\begin{aligned}
n_{I}\left(y, x_{I}, p\right) & =\operatorname{Max}\left(\frac{\bar{f}+\theta-p}{a_{I} \sigma_{\epsilon}^{2}} ; \nu\right) \\
& =\operatorname{Max}\left(\frac{\left.\left(1-\lambda_{I}\right) m^{2} \theta+\left[\left(1+m^{2}\right) \sigma_{\epsilon}^{2}+m^{2}\right)\right]\left(a_{U} \bar{n}-\lambda_{I} a_{U} \nu\right)}{a_{I} \sigma_{\epsilon}^{2}\left(1-\lambda_{I}\right)\left(1+m^{2}\right)} ; \nu\right) \\
& =\nu \text { if } \theta \leqslant \underline{\theta}
\end{aligned}
$$

It can easily be checked that any price $p$ such that $p(\underline{\theta}) \geqslant p \geqslant p\left(\theta^{*}\right)$ corresponds to one and only one $\theta$. Thus prices reveal $\theta$ in Region $C$ and, from the study of the unconstrained economy, the demand of the uninformed trader is given by:

$$
n_{U}(p)=\operatorname{Max}\left(\frac{\left(1+m^{2}\right)(\bar{f}-p)+\theta}{a_{U}\left(\left(1+m^{2}\right) \sigma_{\epsilon}^{2}+m^{2}\right)} ; \nu\right)=\operatorname{Max}\left(\frac{\bar{n}-\lambda_{I} \nu}{1-\lambda_{I}} ; \nu\right)=\frac{\bar{n}-\lambda_{I} \nu}{1-\lambda_{I}}
$$

since $\nu<N$. Thus, the market clearing condition is satisfied in Region $C$.

Region D. We first need to show that $t^{*}$ is well defined. First notice that the LHS of equation (2.3) is a continuous function of $t$ and that its limit when $t \rightarrow+\infty$ is equal to $+\infty$. Applying L'Hospital rule twice, one can show that the limit of the LHS of equation (2.3) when $t \rightarrow-\infty$ is equal to $-\infty$. Thus, equation (2.3) has at least one root and there exists $t^{*}$ such that for any $t \leqslant t^{*}$ :

$$
t+\frac{1}{\sqrt{1+m^{2}}} \frac{f\left(\frac{t+a_{U} \frac{\bar{n}-\lambda_{I} \nu}{1-\lambda_{I}}}{\sqrt{1+m^{2}}}\right)}{F\left(\frac{t+a_{U} \frac{\bar{n}-\lambda_{I} \nu}{1-\lambda_{I}}}{\sqrt{1+m^{2}}}\right)}+a_{U}\left(1+\sigma_{\epsilon}^{2}\right) \frac{\bar{n}-\lambda_{I} \nu}{1-\lambda_{I}} \leqslant v a_{I} \sigma_{\epsilon}^{2}
$$

For insiders, we have as before:

$$
n_{I}\left(y, x_{I}, p\right)=\operatorname{Max}\left(\frac{\bar{f}+\theta-P}{a_{I} \sigma_{\epsilon}^{2}} ; \nu\right)=\nu
$$


The last expression follows from the fact that $\theta^{*} \leqslant t^{*}$ implies:

$$
\frac{\bar{f}+\theta-P}{a_{I} \sigma_{\epsilon}^{2}}=\frac{1}{a_{I} \sigma_{\epsilon}^{2}}\left(\theta+\frac{1}{\sqrt{1+m^{2}}} \frac{f\left(\frac{\theta^{*}+a_{U} \frac{\bar{n}-\lambda_{I} \nu}{1-\lambda_{I}}}{\sqrt{1+m^{2}}}\right)}{F\left(\frac{\theta^{*}+a_{U} \frac{\bar{n}-\lambda_{I} \nu}{1-\lambda_{I}}}{\sqrt{1+m^{2}}}\right)}+a_{U}\left(1+\sigma_{\epsilon}^{2}\right) \frac{\bar{n}-\lambda_{I} \nu}{1-\lambda_{I}}\right)<\nu
$$

Notice that the equilibrium price is constant in Region $D$ and different from the equilibrium price in any of the other three regions. Indeed, it is easy to show that it is strictly smaller. Using the expressions in Theorem 1, we have:

$p_{c}\left(\theta^{*}\right)-p^{*}=\frac{\theta^{*}}{1+m^{2}}+\frac{1}{1+m^{2}} \frac{a_{U}\left(\bar{n}-\lambda_{I} \nu\right)}{1-\lambda_{I}}+\frac{1}{\sqrt{1+m^{2}}} \frac{f\left(\frac{\theta^{*}}{\sqrt{1+m^{2}}}+\frac{1}{\sqrt{1+m^{2}}} \frac{a_{U}\left(\bar{n}-\lambda_{I} \nu\right)}{1-\lambda_{I}}\right)}{F\left(\frac{\theta^{*}}{\sqrt{1+m^{2}}}+\frac{1}{\sqrt{1+m^{2}}} \frac{a_{U}\left(\bar{n}-\lambda_{I} \nu\right)}{1-\lambda_{I}}\right)}$ or,

$$
p_{c}\left(\theta^{*}\right)-p^{*}=\frac{1}{\sqrt{1+m^{2}}}\left(x+\frac{f(x)}{F(x)}\right)
$$

where, $x \equiv \frac{\theta^{*}}{\sqrt{1+m^{2}}}+\frac{1}{\sqrt{1+m^{2}}} \frac{a_{U}\left(\bar{n}-\lambda_{I} \nu\right)}{1-\lambda_{I}}$.

Since $f(\cdot)$ and $F(\cdot)$ are the density and the CDF of the normal distribution, respectively, it is immediate that $x+\frac{f(x)}{F(x)}>0$, since $x \int_{-\infty}^{x} e^{-\frac{1}{2} t^{2}} d t>\int_{-\infty}^{x} t e^{-\frac{1}{2} t^{2}} d t=$ $-e^{-\frac{1}{2} x^{2}}$. This proves that $p_{c}\left(\theta^{*}\right)>p^{*}$.

Therefore observing the equilibrium price of Region $D, P(\theta)=p^{*}$ is equivalent to observing that $\theta<\theta^{*}$. Thus the expected utility of an uninformed agent who observes the equilibrium price in Region $D$ can be written as follows:

$$
\begin{aligned}
& E\left[U\left(w_{U}\right) \mid P=p^{*}\right]=-E\left[e^{-a_{U} n_{U}(\bar{f}+y+\epsilon-P)} \mid \theta<\theta^{*}\right]= \\
& =-\frac{1}{F\left(\theta^{*}\right)} \int_{-\infty}^{\theta^{*}} E\left[e^{-a_{U} n_{U}(\bar{f}+y+\epsilon-P)} \mid \theta\right] f(\theta) d \theta \\
& =-\frac{\left.e^{-a_{U} n_{U}(\bar{f}-P)}\right\}}{F\left(\theta^{*}\right)} \int_{-\infty}^{\theta^{*}} \exp \left(-a_{U} n_{U} E(y \mid \theta)+\frac{1}{2} a_{U}^{2} n_{U}^{2}\left(\operatorname{Var}(y \mid \theta)+\sigma_{\epsilon}^{2}\right)\right) f(\theta) d \theta \\
& =-\frac{e^{-a_{U} n_{U}(\bar{f}-P)+\frac{1}{2} a_{U}^{2} n_{U}^{2}\left(\frac{m^{2}}{1+m^{2}}+\sigma_{\epsilon}^{2}\right)}}{F\left(\theta^{*}\right)} \int_{-\infty}^{\theta^{*}} \exp \left(-a_{U} n_{U} \frac{\theta}{1+m^{2}}\right) f(\theta) d \theta \\
& =-\frac{e^{-a_{U} n_{U}(\bar{f}-P)+\frac{1}{2} a_{U}^{2} n_{U}^{2}\left(1+\sigma_{\epsilon}^{2}\right)}}{F\left(\theta^{*}\right)} F\left(\frac{\theta^{*}+a_{U} n_{U}}{\sqrt{1+m^{2}}}\right)
\end{aligned}
$$


Taking the first order conditions and dividing left and right by $\frac{a_{U}}{F\left(\frac{\theta^{*}+a_{U} n_{U}}{\sqrt{1+m^{2}}}\right)}$, we find that the demand of the uninformed trader, $n_{U}$, must satisfy the following condition:

$$
\frac{1}{\sqrt{1+m^{2}}} \frac{f\left(\frac{\theta^{*}+a_{U} n_{U}}{\sqrt{1+m^{2}}}\right)}{F\left(\frac{\theta^{*}+a_{U} n_{U}}{\sqrt{1+m^{2}}}\right)}+P-\bar{f}+a_{U}\left(1+\sigma_{\epsilon}^{2}\right) n_{U}=0
$$

It is straightforward to check that the equilibrium prices and holdings given in the Theorem for Region $D$ satisfy both the above equation (optimality) and market clearing. 


\section{A.2 Figures}

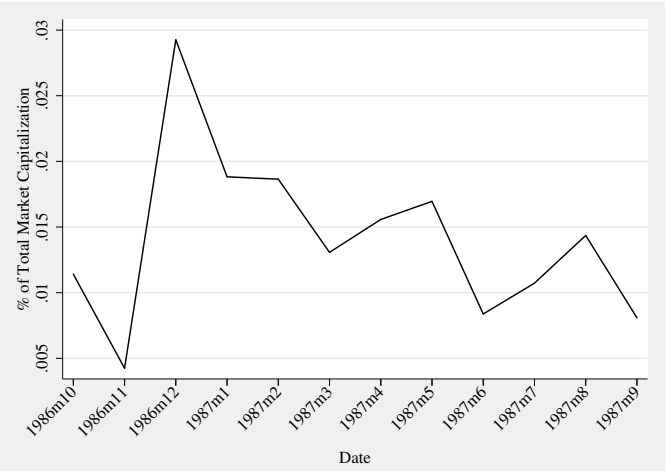

(a) Managers sales before October, 1987 (Largest S\&P 500 "drop" in period 19862002)

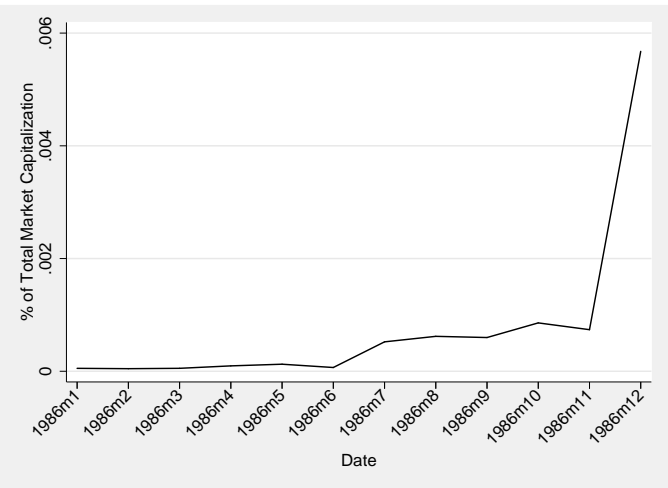

(b) Managers purchases before January, 1987 (Largest S\&P 500 "jump" in period 1986-2002)

Figure 1: Managers transactions before large market movements.

This graphs show the evolution of managers' open market or private trades in common stocks traded in NYSE, AMEX and Nasdaq that appear in the CRSP dataset, before the largest market movements in the S\&P 500 during the 1986-2002 period. The data on insider transactions comes from Thompson Financial Data Fillings dataset. We exclude stocks with price smaller than $\$ 2$ at the beginning of each calendar year, amended insider trading records, transactions involving less than 100 shares, and fillings in which the reported transaction price was not within $20 \%$ of the CRSP closing price on that day, or that involved more than $20 \%$ of the number of shares outstanding. We consider as managers the chairman, directors, CEOs, CFOs, officers, presidents, vice presidents, affiliate persons, members of committees, etc. \% of Total Market Capitalization is defined as 100 times the value of all the managers trades during the month (number of shares traded times the transaction price or the closing price of the day if the transaction price is missing) divided by the total market value of our universe of firms at the beginning of the month. 


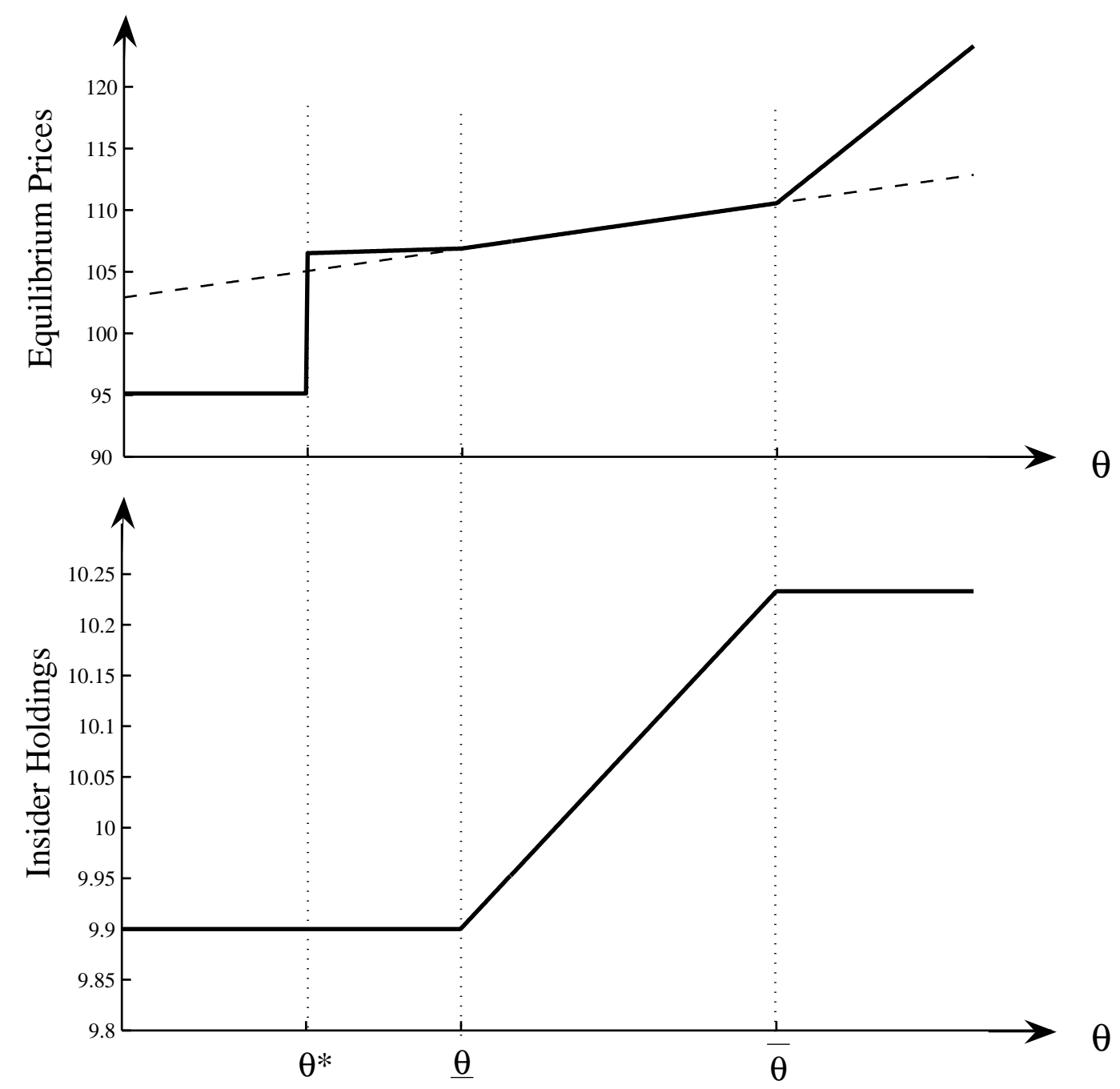

Figure 2: Equilibrium prices and insider holdings.

This figure displays a parametric example of the equilibrium (prices and holdings) described in Theorem 1 resulting in a $10 \%$ crash. The parameter values are: $a_{I}=1, a_{U}=0.4, \lambda_{I}=0.3, \bar{n}=10, \sigma_{\epsilon}^{2}=50, \nu=9.90$, $\sigma_{\epsilon z}^{2}=1, k_{I}=5$, and $\bar{f}=300$. 


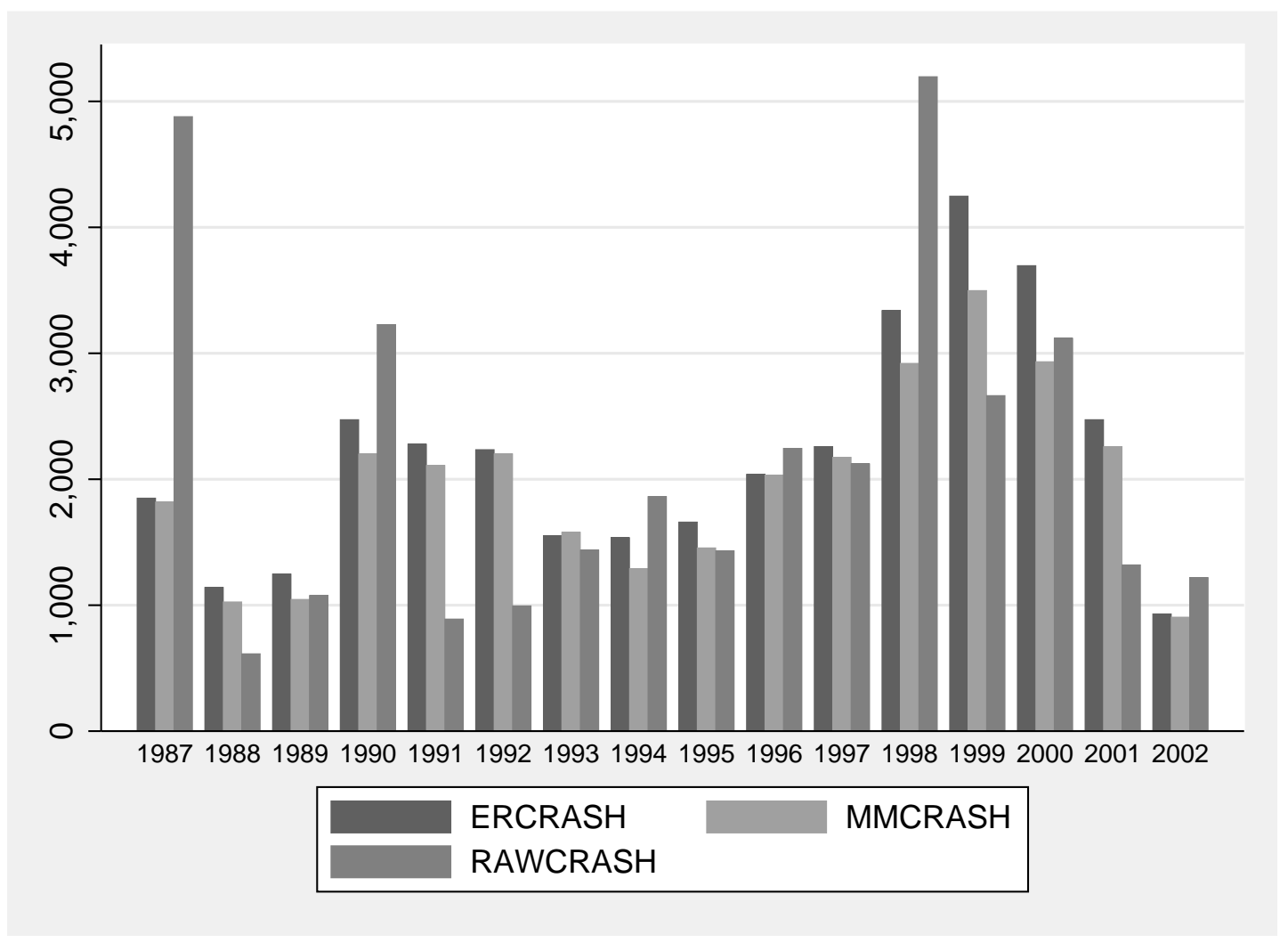

Figure 3: Number of crashes over time.

The figure reports the evolution of the aggregate number of crashes for common stocks traded in NYSE, AMEX and Nasdaq that appear in CRSP dataset, excluding stocks with a price smaller than $\$ 2$ at the beginning of each calendar year. The figure is reported for the following alternative definitions of a crash:

$$
\begin{aligned}
& E R C R A S H_{i, t}= \begin{cases}1, & \text { if } r_{i, t}^{E R}-\bar{r}_{i, t}^{E R} \leq-2 \sigma_{i, t}^{E R} \\
0, & \text { otherwise. }\end{cases} \\
& M M C R A S H_{i, t}= \begin{cases}1, & \text { if } r_{i, t}^{M M}-\bar{r}_{i, t}^{M M} \leq-2 \sigma_{i, t}^{M M} \\
0, & \text { otherwise. }\end{cases} \\
& R A W C R A S H_{i, t}= \begin{cases}1, & \text { if } r_{i, t}-\bar{r}_{i, t} \leq-2 \sigma_{i, t} \\
0, & \text { otherwise. }\end{cases}
\end{aligned}
$$

where: $r_{i, t}^{E R} \equiv r_{i, t}-r_{m, t}, r_{i, t}^{M M} \equiv r_{i, t}-\left(r_{f, t}+\beta_{i, t}\left(r_{m, t}-r_{f, t}\right)\right), r_{i, t}$ is the raw return of stock $i$ in month $t, r_{m, t}$ is the monthly return of the CRSP equally weighted market portfolio, $\beta_{i, t}$ is the beta of the stock estimated over a sixty-month rolling window and $r_{f, t}$ is the risk-free rate. $\bar{r}_{i, t}^{k}$ and $\sigma_{i, t}^{k}, k=E R, M M, \emptyset$, denote the sample mean and standard deviation of the corresponding $k$ variable and are computed using a five-year rolling window. 


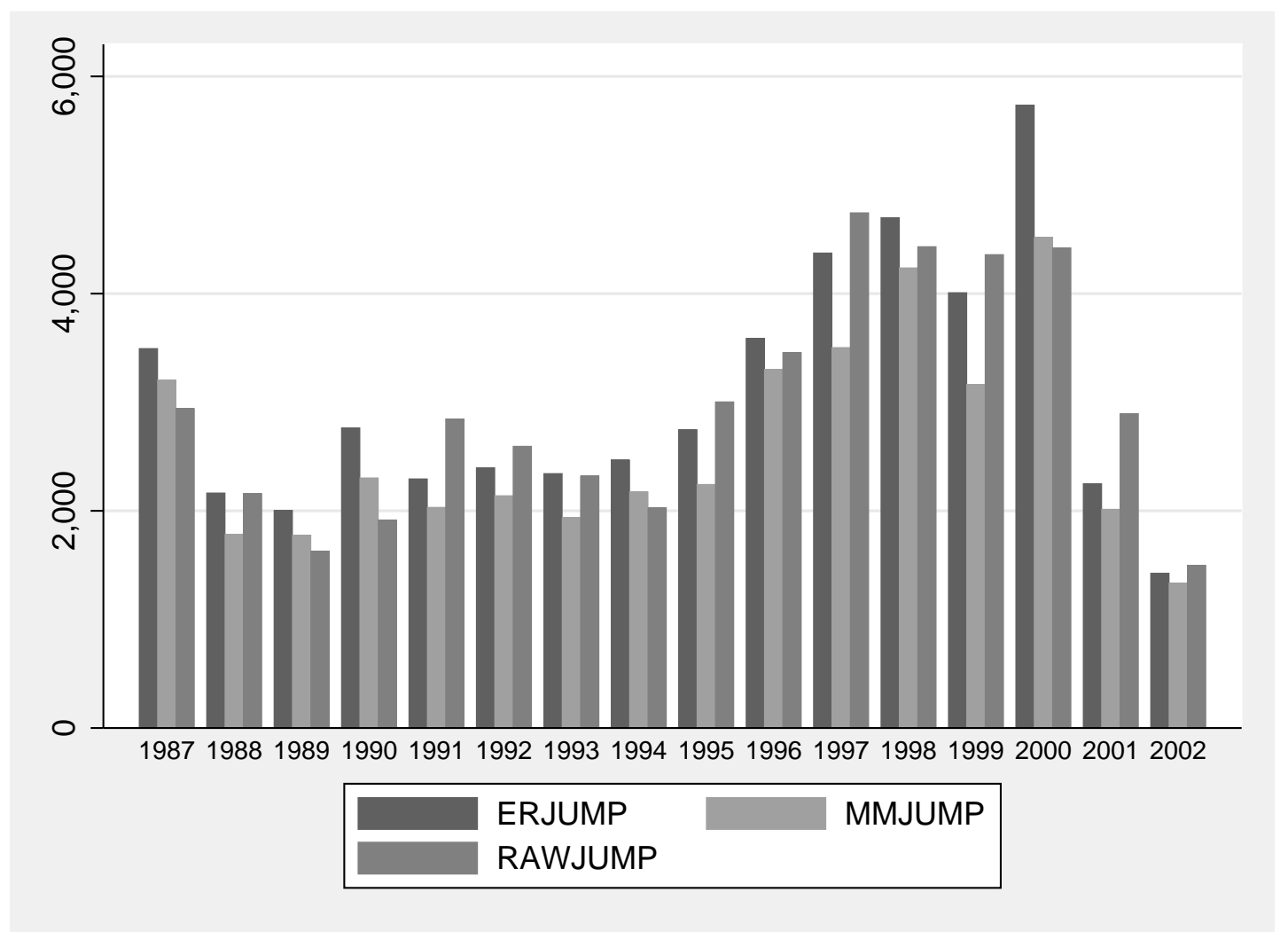

Figure 4: Number of jumps over time.

The figure reports the evolution of the aggregate number of jumps for common stocks traded in NYSE, AMEX and Nasdaq that appear in CRSP dataset, excluding stocks with a price smaller than $\$ 2$ at the beginning of each calendar year. The figure is reported for the following alternative definitions of a jump:

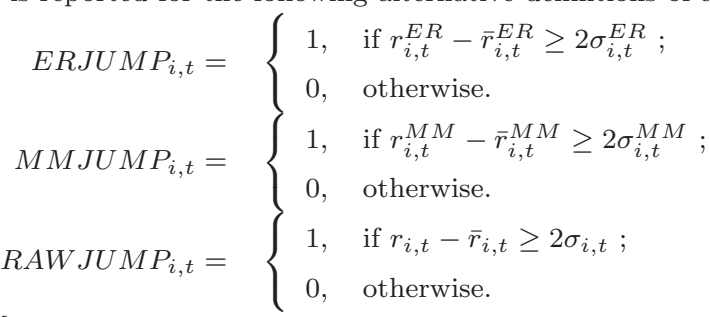

where: $r_{i, t}^{E R} \equiv r_{i, t}-r_{m, t}, r_{i, t}^{M M} \equiv r_{i, t}-\left(r_{f, t}+\beta_{i, t}\left(r_{m, t}-r_{f, t}\right)\right), r_{i, t}$ is the raw return of stock $i$ in month $t, r_{m, t}$ is the monthly return of the CRSP equally weighted market portfolio, $\beta_{i, t}$ is the beta of the stock estimated over a sixty-month rolling window and $r_{f, t}$ is the risk-free rate. $\bar{r}_{i, t}^{k}$ and $\sigma_{i, t}^{k}, k=E R, M M, \emptyset$, denote the sample mean and standard deviation of the corresponding $k$ variable and are computed using a five-year rolling window. 


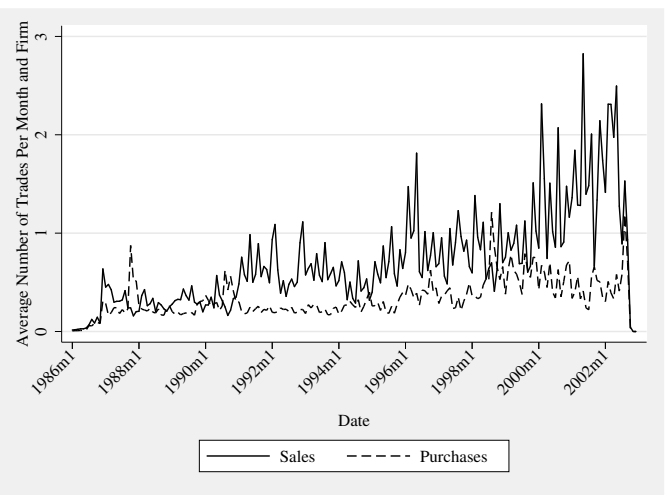

(a) Insider transactions: average number of trades

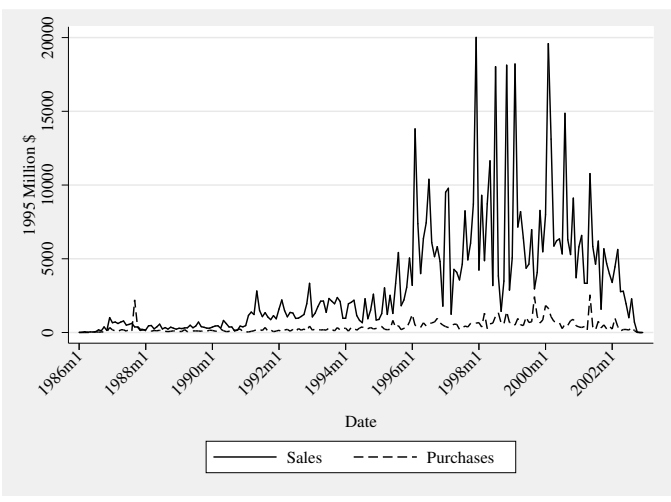

(b) Insider transactions: total monthly dollar volume

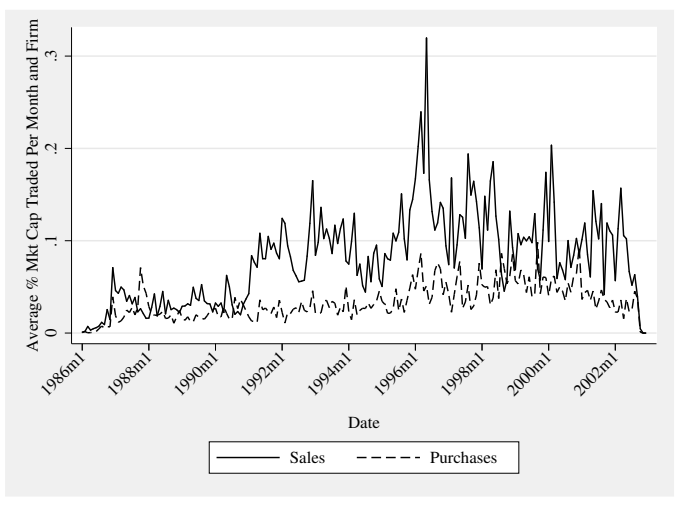

(c) Insider transactions: average fraction of firm's market capitalization

Figure 5: Evolution of insider trading activity.

These figures show the evolution over time of several measures of aggregate insider trading activity. Panel (a) plots the average number of sales and purchases per month and firm, and includes companies without any trading; panel (b) the total monthly dollar value of insider sales and purchases expressed in terms of 1995 million dollars; panel (c) the average monthly fraction of insider sales and purchases to company market capitalization, where market capitalization is computed using the closing price of the day of the trade. The sample consists of insiders open market or private sales and purchases from 1986 to 2002 in common stocks traded in NYSE, AMEX and Nasdaq markets that appear in CRSP dataset; the data on insider transactions comes from Thompson Financial Data Fillings dataset. We exclude stocks with a price smaller than $\$ 2$ at the beginning of each calendar year, amended insider trading records, transactions involving less than 100 shares, and fillings in which the reported transaction price was not within $20 \%$ of the CRSP closing price on that day,or that involved more than the $20 \%$ of the number of shares outstanding. 


\section{A.3 Tables}

Table 1: Correlation between number of crashes.

\begin{tabular}{c|ccc} 
& ERCRASH & MMCRASH & RAWCRASH \\
\hline ERCRASH & 1 & & \\
MMCRASH & 0.7145 & 1 & \\
RAWCRASH & 0.5291 & 0.4906 & 1
\end{tabular}

The table reports the correlation matrix for the number of crashes for the period 1987-2002, for common stocks traded in NYSE, AMEX and Nasdaq that appear in CRSP dataset, excluding stocks with a price smaller than $\$ 2$ at the beginning of each calendar year, under the following three alternative definitions of a crash:

$$
\begin{aligned}
& \operatorname{ERCRASH}_{i, t}= \begin{cases}1, & \text { if } r_{i, t}^{E R}-\bar{r}_{i, t}^{E R} \leq-2 \sigma_{i, t}^{E R} \\
0, & \text { otherwise. }\end{cases} \\
& M M C R A S H_{i, t}= \begin{cases}1, & \text { if } r_{i, t}^{M M}-\bar{r}_{i, t}^{M M} \leq-2 \sigma_{i, t}^{M M} \\
0, & \text { otherwise. }\end{cases} \\
& R A W C R A S H_{i, t}= \begin{cases}1, & \text { if } r_{i, t}-\bar{r}_{i, t} \leq-2 \sigma_{i, t} \\
0, & \text { otherwise. }\end{cases}
\end{aligned}
$$

where: $r_{i, t}^{E R} \equiv r_{i, t}-r_{m, t}, r_{i, t}^{M M} \equiv r_{i, t}-\left(r_{f, t}+\beta_{i, t}\left(r_{m, t}-r_{f, t}\right)\right), r_{i, t}$ is the raw return of stock $i$ in month $t, r_{m, t}$ is the monthly return of the CRSP equally weighted market portfolio, $\beta_{i, t}$ is the beta of the stock estimated over a sixty-month rolling window and $r_{f, t}$ is the risk-free rate. $\bar{r}_{i, t}^{k}$ and $\sigma_{i, t}^{k}, k=E R, M M, \emptyset$, denote the sample mean and standard deviation of the corresponding $k$ variable and are computed using a five-year rolling window. 
Table 2: Correlation between number of jumps.

\begin{tabular}{c|ccc} 
& ERJUMP & MMJUMP & RAWJUMP \\
\hline ERJUMP & 1 & & \\
MMJUMP & 0.7815 & 1 & \\
RAWJUMP & 0.7429 & 0.7003 & 1
\end{tabular}

The table reports the correlation matrix for the number of jumps for the period 1987-2002, for common stocks traded in NYSE, AMEX and Nasdaq that appear in CRSP dataset, excluding stocks with a price smaller than $\$ 2$ at the beginning of each calendar year, under the following three alternative definitions of a jump:

$$
\operatorname{ERJUMP} P_{i, t}= \begin{cases}1, & \text { if } r_{i, t}^{E R}-\bar{r}_{i, t}^{E R} \geq 2 \sigma_{i, t}^{E R} ; \\ \operatorname{MMJU} M P_{i, t} & \text { otherwise. } \\ 1, & \text { if } r_{i, t}^{M M}-\bar{r}_{i, t}^{M M} \geq 2 \sigma_{i, t}^{M M} \\ 0, & \text { otherwise. } \\ 1, & \text { if } r_{i, t}-\bar{r}_{i, t} \geq 2 \sigma_{i, t} ; \\ 0, & \text { otherwise. }\end{cases}
$$

where: $r_{i, t}^{E R} \equiv r_{i, t}-r_{m, t}, r_{i, t}^{M M} \equiv r_{i, t}-\left(r_{f, t}+\beta_{i, t}\left(r_{m, t}-r_{f, t}\right)\right), r_{i, t}$ is the raw return of stock $i$ in month $t, r_{m, t}$ is the monthly return of the CRSP equally weighted market portfolio, $\beta_{i, t}$ is the beta of the stock estimated over a sixty-month rolling window and $r_{f, t}$ is the risk-free rate. $\bar{r}_{i, t}^{k}$ and $\sigma_{i, t}^{k}, k=E R, M M, \emptyset$, denote the sample mean and standard deviation of the corresponding $k$ variable and are computed using a five-year rolling window. 
Table 3: Insider trading activity: summary statistics.

\begin{tabular}{rrrrr}
\hline \hline & \multicolumn{4}{c}{ Large } \\
& Management & Shareholders & Others & Total \\
\cline { 2 - 5 } Purchases & & & & \\
Fraction & 0.483 & 0.052 & 0.013 & 0.501 \\
\# of Trades & 2.927 & 0.845 & 0.052 & 3.824 \\
Tot Million $\$$ & $\$ 1,891$ & $\$ 2,482$ & $\$ 94$ & $\$ 4,467$ \\
$\%$ Mkt Cap & $0.213 \%$ & $0.168 \%$ & $0.008 \%$ & $0.388 \%$ \\
Sales & & & & \\
Fraction & 0.509 & 0.088 & 0.031 & 0.531 \\
\# of Trades & 6.838 & 1.000 & 0.136 & 7.975 \\
Tot Million $\$$ & $\$ 24,045$ & $\$ 13,394$ & $\$ 783$ & $\$ 38,222$ \\
$\%$ Mkt Cap & $0.561 \%$ & $0.348 \%$ & $0.023 \%$ & $0.932 \%$ \\
\hline \hline
\end{tabular}

This table presents some summary statistics on aggregate insider trading activity. Fraction, shows the average fraction of firms with at least one insider trade per year; \# of Trades, is the average number of sales or purchases per year and firm, and includes companies without any trading; Tot Million $\$$ is the average of the annual dollar value of insider trades per year expressed in terms of 1995 million dollars. \% Mkt Cap is the ratio of the average of the value of insiders trades per company and year to market capitalization in percentage terms, where market capitalization is computed using the closing price of the day of the trade. The sample consists of insiders open market or private sales and purchases from 1986 to 2002 in common stocks traded in NYSE, AMEX and Nasdaq markets that appear in CRSP dataset; the data on insider transactions comes from Thompson Financial Data Fillings dataset. We exclude stocks with a price smaller than $\$ 2$ at the beginning of each calendar year, amended insider trading records, transactions involving less than 100 shares, and fillings in which the reported transaction price was not within $20 \%$ of the CRSP closing price on that day, or that involved more than the $20 \%$ of the number of shares outstanding. 
Table 4: Preliminary regression: insiders trading volume and crashes.

\begin{tabular}{lcc}
\hline \hline & $(1)$ & $(2)$ \\
\cline { 2 - 3 }$I N S T V_{t-1}$ & ERCRASH & MMCRASH \\
& $-0.039^{* *}$ & $-0.032^{* *}$ \\
INSTV & $(0.011)$ & $(0.010)$ \\
& $0.090+$ & 0.039 \\
$E R_{t-1, t-24}$ & $(0.053)$ & $(0.047)$ \\
& $0.001^{* *}$ & $0.001^{* *}$ \\
$T T V_{t-1}$ & $(0.000)$ & $(0.000)$ \\
& $0.015^{* *}$ & $0.012^{* *}$ \\
$T T V_{t-2, t-12}$ & $(0.002)$ & $(0.002)$ \\
& -0.002 & $0.012^{* *}$ \\
Observations & $(0.003)$ & $(0.003)$ \\
\hline Standard errors in parentheses & 789658 \\
+ significant at $10 \% ; *$ significant at $5 \% ;$ & $* *$ significant at $1 \%$ \\
\hline \hline
\end{tabular}

In columns 1 and 2 we report the results obtained in the following two preliminary regressions for crashes:

$$
\begin{aligned}
\operatorname{ERCRASH}_{i, t}=\quad & \alpha_{i}+\gamma_{t}+\beta_{1} I N S T V_{i, t-1}+\beta_{2} I N S T V_{i, t-2, t-12}+\beta_{3} E R_{i, t-1, t-24} \\
& +\beta_{4} T T V_{i, t-1}+\beta_{4} T T V_{i, t-2, t-12}+\epsilon_{i, t} \\
M_{M C R A S H}= & \alpha_{i}+\gamma_{t}+\beta_{1} I N S T V_{i, t-1}+\beta_{2} I N S T V_{i, t-2, t-12}+\beta_{3} E R_{i, t-1, t-24} \\
& +\beta_{4} T T V_{i, t-1}+\beta_{4} T T V_{i, t-2, t-12}+\epsilon_{i, t}
\end{aligned}
$$

where $i$ and $t$ are indexes for the company and the calendar month, respectively. In the estimation we use the Newey-West standard errors to control for autocorrelation and heteroscedasticity. The dependent variables are defined as:

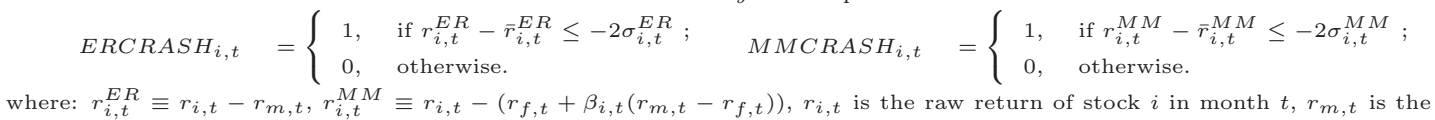
monthly return of the CRSP equally weighted market portfolio, $\beta_{i, t}$ is the beta of the stock estimated over a sixty-month rolling window and $r_{f, t}$ is the risk-free rate. $\bar{r}_{i, t}^{k}$ and $\sigma_{i, t}^{k}, k=E R, M M, \emptyset$, denote the sample mean and standard deviation of the corresponding $k$ variable and are computed using a five-year rolling window. Regarding the independent variables: $I N S T V_{i, t-1}$ is the past month trading volume by insiders in stock $i, I N S T V_{i, t-2, t-12}$ is the average trading volume by insiders in stock $i$ in the past year (excluding the previous month), $T T V_{i, t-1}$ is the past month total trading volume in stock $i, T T V_{i, t-2, t-12}$ is the average total trading volume in stock $i$ in the past year (excluding the previous month) and $E R_{i, t-1, t-24}$ is stock's $i$ cumulative excess return over the CRSP equally weighted market portfolio for the previous two years. The sample consists of insiders open market or private sales and purchases from 1986 to 2002 in common stocks traded in NYSE, AMEX and Nasdaq markets that appear in CRSP dataset; the data on insider transactions comes from Thompson Financial Data Fillings dataset. We exclude stocks with price smaller than $\$ 2$ at the beginning of each calendar year, amended insider trading records, transactions involving less than 100 shares, and fillings in which the reported transaction price was not within $20 \%$ of the CRSP closing price on that day, or that involved more than the $20 \%$ of the number of shares outstanding. 
Table 5: Leading regression: insider sales and crashes.

\begin{tabular}{lcc}
\hline \hline & $(1)$ & $(2)$ \\
\cline { 2 - 3 }$I N S S A L_{t-1}$ & ERCRASH & MMCRASH \\
& $-0.025+$ & $-0.028^{*}$ \\
INSSAL $L_{t-2, t-12}$ & $(0.013)$ & $(0.011)$ \\
& $0.232^{* *}$ & $0.127^{*}$ \\
$E R_{t-1, t-24}$ & $(0.068)$ & $(0.059)$ \\
& $0.001^{* *}$ & $0.001^{* *}$ \\
$T T V_{t-1}$ & $(0.000)$ & $(0.000)$ \\
& $0.015^{* *}$ & $0.012^{* *}$ \\
$T T V_{t-2, t-12}$ & $(0.002)$ & $(0.002)$ \\
Observations & -0.002 & $0.012^{* *}$ \\
\hline
\end{tabular}

Standard errors in parentheses

+ significant at $10 \% ; *$ significant at $5 \%$; ${ }^{*}$ significant at $1 \%$

In columns 1 and 2 we report the results obtained in the following two leading regressions for crashes:

$$
\begin{aligned}
\operatorname{ERCRASH} H_{i, t}= & \alpha_{i}+\gamma_{t}+\beta_{1} I N S S A L_{i, t-1}+\beta_{2} I N S S A L_{i, t-2, t-12}+\beta_{3} E R_{i, t-1, t-24} \\
& +\beta_{4} T T V_{i, t-1}+\beta_{4} T T V_{i, t-2, t-12}+\epsilon_{i, t} \\
M M C R A S H_{i, t}= & \alpha_{i}+\gamma_{t}+\beta_{1} I N S S A L_{i, t-1}+\beta_{2} I N S S A L_{i, t-2, t-12}+\beta_{3} E R_{i, t-1, t-24} \\
& +\beta_{4} T T V_{i, t-1}+\beta_{4} T T V_{i, t-2, t-12}+\epsilon_{i, t}
\end{aligned}
$$

where $i$ and $t$ are indexes for the company and the calendar month, respectively. In the estimation we use the Newey-West standard errors to control for autocorrelation and heteroscedasticity. The dependent variables are defined as:

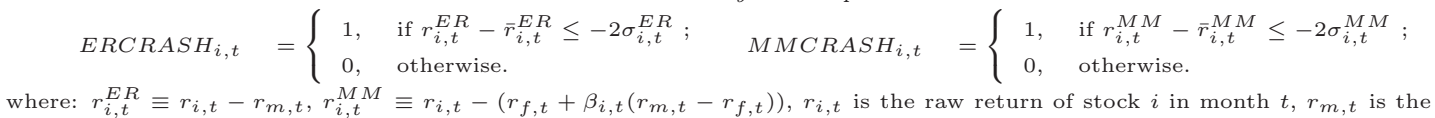
monthly return of the CRSP equally weighted market portfolio, $\beta_{i, t}$ is the beta of the stock estimated over a sixty-month rolling window and $r_{f, t}$ is the risk-free rate. $\bar{r}_{i, t}^{k}$ and $\sigma_{i, t}^{k}, k=E R, M M, \emptyset$, denote the sample mean and standard deviation of the corresponding $k$ variable and are computed using a five-year rolling window. Regarding the independent variables: $I N S S A L_{i, t}-1$ are the past month insiders' sales in stock $i, I N S S A L_{i, t-2, t-12}$ is the average of the insiders sales in stock $i$ during the period $t-12$ to $t-2, T T V_{i, t-1}$ is the past month total trading volume in stock $i, T T V_{i, t-2, t-12}$ is the average total trading volume in stock $i$ during the period $t-12$ to $t-2$ and $E R_{i, t-1, t-24}$ is stock's $i$ cumulative excess return over the CRSP equally weighted market portfolio for the previous two years. The sample consists of insiders open market or private sales and purchases from 1986 to 2002 in common stocks traded in NYSE, AMEX and Nasdaq markets that appear in CRSP dataset; the data on insider transactions comes from Thompson Financial Data Fillings dataset. We exclude stocks with price smaller than $\$ 2$ at the beginning of each calendar year, amended insider trading records, transactions involving less than 100 shares, and fillings in which the reported transaction price was not within $20 \%$ of the CRSP closing price on that day, or that involved more than the $20 \%$ of the number of shares outstanding. 
Table 6: Leading regression: insider purchases and jumps.

\begin{tabular}{lcc}
\hline \hline & $(1)$ & $(2)$ \\
\cline { 2 - 3 }$I N S P U R C H_{t-1}$ & ERJUMP & MMJUMP \\
& $0.087+$ & $0.087^{*}$ \\
INSPURCH $H_{t-2, t-12}$ & $(0.044)$ & $(0.043)$ \\
& 0.162 & 0.171 \\
$E R_{t-1, t-24}$ & $(0.140)$ & $(0.130)$ \\
& $-0.007^{* *}$ & $-0.006^{* *}$ \\
$T T V_{t-1}$ & $(0.001)$ & $(0.000)$ \\
& $0.015^{* *}$ & $0.010^{* *}$ \\
$T T V_{t-2, t-12}$ & $(0.003)$ & $(0.002)$ \\
Observations & $-0.070^{* *}$ & $-0.056^{* *}$ \\
\hline
\end{tabular}

Standard errors in parentheses

+ significant at $10 \% ;{ }^{*}$ significant at $5 \%$; $*$ significant at $1 \%$

In columns 1 and 2 we report the results obtained in the following two leading regressions for jumps: ERJUMP $P_{i, t}=\alpha_{i}+\gamma_{t}+\beta_{1} I N S P U R C H_{i, t-1}+\beta_{2} I N S P U R C H_{i, t-2, t-12}$ $+\beta_{3} E R_{i, t-1, t-24}+\beta_{4} T T V_{i, t-1}+\beta_{4} T T V_{i, t-2, t-12}+\epsilon_{i, t}$ MMJUMP $P_{i, t}=\alpha_{i}+\gamma_{t}+\beta_{1} I N S P U R C H_{i, t-1}+\beta_{2} I N S P U R C H_{i, t-2, t-12}$ $+\beta_{3} E R_{i, t-1, t-24}+\beta_{4} T T V_{i, t-1}+\beta_{4} T T V_{i, t-2, t-12}+\epsilon_{i, t}$

where $i$ and $t$ are indexes for the company and the calendar month, respectively. In the estimation we use the Newey-West standard errors to control for autocorrelation and heteroscedasticity. The dependent variables are defined as:

$$
E R J U M P_{i, t}=\left\{\begin{array}{ll}
1, & \text { if } r_{i, t}^{E R}-\bar{r}_{i, t}^{E R} \geq 2 \sigma_{i, t}^{E R} ; \quad M M J U M P_{i, t} \\
0, & \text { otherwise. }
\end{array}= \begin{cases}1, & \text { if } r_{i, t}^{M M}-\bar{r}_{i, t}^{M M} \geq 2 \sigma_{i, t}^{M M} \\
0, & \text { otherwise. }\end{cases}\right.
$$

where: $r_{i, t}^{E R} \equiv r_{i, t}-r_{m, t}, r_{i, t}^{M M} \equiv r_{i, t}-\left(r_{f, t}+\beta_{i, t}\left(r_{m, t}-r_{f, t}\right)\right), r_{i, t}$ is the raw return of stock $i$ in month $t, r_{m, t}$ is the monthly return of the CRSP equally weighted market portfolio, $\beta_{i, t}$ is the beta of the stock estimated over a sixty-month rolling window and $r_{f, t}$ is the risk-free rate. $\bar{r}_{i, t}^{k}$ and $\sigma_{i, t}^{k}, k=E R, M M, \emptyset$, denote the sample mean and standard deviation of the corresponding $k$ variable and are computed using a five-year rolling window. Regarding the independent variables: $I N S P U R C H_{i, t-1}$ are the past month insiders' purchases in stock $i, I N S P U R C H_{i, t-2, t-12}$ is the average of the insiders purchases in stock $i$ during the period $t-12$ to $t-2, T T V_{i, t-1}$ is the past month total trading volume in stock $i, T T V_{i, t-2, t-12}$ is the average total trading volume in stock $i$ during the period $t-12$ to $t-2$ and $E R_{i, t-1, t-24}$ is stock's $i$ cumulative excess return over the CRSP equally weighted market portfolio for the previous two years. The sample consists of insiders open market or private sales and purchases from 1986 to 2002 in common stocks traded in NYSE, AMEX and Nasdaq markets that appear in CRSP dataset; the data on insider transactions comes from Thompson Financial Data Fillings dataset. We exclude stocks with price smaller than $\$ 2$ at the beginning of each calendar year, amended insider trading records, transactions involving less than 100 shares, and fillings in which the reported transaction price was not within $20 \%$ of the CRSP closing price on that day, or that involved more than the $20 \%$ of the number of shares outstanding. 


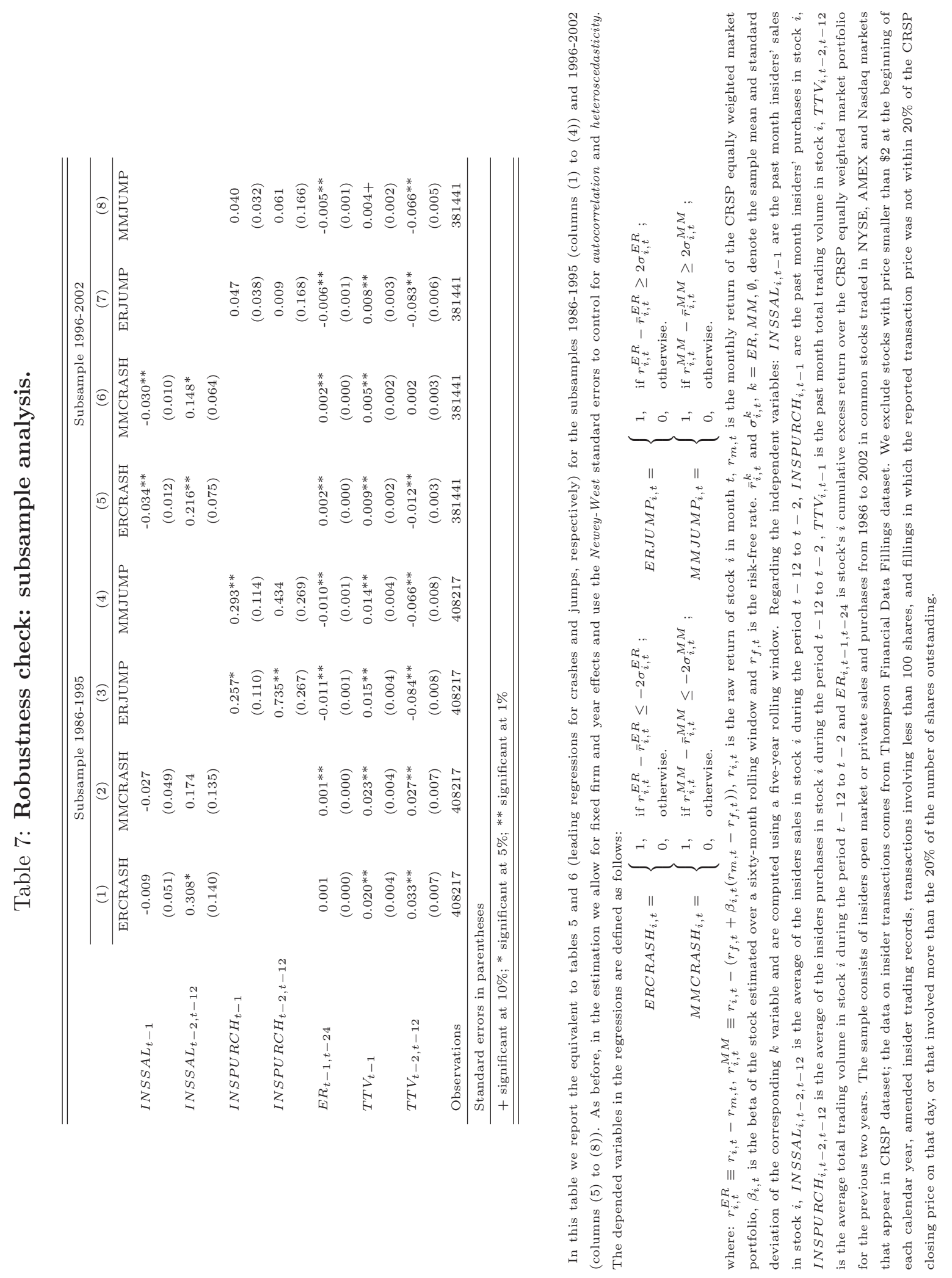


Table 8: Robustness checks: the logit model.

\begin{tabular}{|c|c|c|c|c|}
\hline & (1) & (2) & (3) & (4) \\
\hline & ERCRASH & MMCRASH & ERJUMP & MMJUMP \\
\hline \multirow[t]{2}{*}{$I N S S A L_{t-1}$} & $-2.476^{*}$ & $-3.564^{*}$ & & \\
\hline & $(1.122)$ & $(1.404)$ & & \\
\hline \multirow[t]{2}{*}{$I N S S A L_{t-2, t-12}$} & $2.970+$ & -1.196 & & \\
\hline & $(1.523)$ & $(1.916)$ & & \\
\hline \multirow[t]{2}{*}{$E R_{t-1, t-24}$} & -0.010 & -0.003 & $-0.280^{* *}$ & $-0.265^{* *}$ \\
\hline & $(0.006)$ & $(0.005)$ & $(0.013)$ & $(0.012)$ \\
\hline \multirow[t]{2}{*}{$T T V_{t-1}$} & $0.234^{* *}$ & $0.194^{* *}$ & $0.367^{* *}$ & $0.305^{* *}$ \\
\hline & $(0.040)$ & $(0.034)$ & $(0.045)$ & $(0.039)$ \\
\hline \multirow[t]{2}{*}{$T T V_{t-2, t-12}$} & $-0.619^{* *}$ & -0.002 & $-0.878^{* *}$ & $-1.098^{* *}$ \\
\hline & $(0.072)$ & $(0.059)$ & $(0.080)$ & $(0.081)$ \\
\hline \multirow[t]{2}{*}{$I N S P U R C H_{t-1}$} & & & $0.811+$ & $0.912^{*}$ \\
\hline & & & $(0.433)$ & $(0.442)$ \\
\hline \multirow[t]{2}{*}{ INSPURCH $H_{t-2, t-12}$} & & & 0.439 & 1.920 \\
\hline & & & $(2.388)$ & $(2.477)$ \\
\hline Observations & 789658 & 789658 & 789658 & 789658 \\
\hline \multicolumn{5}{|c|}{ Standard errors in parentheses } \\
\hline \multicolumn{5}{|c|}{+ significant at $10 \% ;{ }^{*}$ significant at $5 \% ; * *$ significant at $1 \%$} \\
\hline
\end{tabular}

In this table we report the estimation of the logit version of our leading regressions for crashes and jumps. In the estimation we only allow for year effects and use the Newey-West standard errors to control for autocorrelation and heteroscedasticity. The depended variables in the regressions are defined as follows:

$$
\operatorname{ERCRASH}_{i, t}=\left\{\begin{array}{ll}
1, & \text { if } r_{i, t}^{E R}-\bar{r}_{i, t}^{E R} \leq-2 \sigma_{i, t}^{E R} ; \\
0, & \text { otherwise. } \\
1, & \text { if } r_{i, t}^{M M}-\bar{r}_{i, t}^{M M} \leq-2 \sigma_{i, t}^{M M} ; \\
0, & \text { otherwise. }
\end{array} \quad \text { ERJUMP } P_{i, t}= \begin{cases}1, & \text { if } r_{i, t}^{E R}-\bar{r}_{i, t}^{E R} \geq 2 \sigma_{i, t}^{E R} \\
0, & \text { otherwise. }\end{cases}\right.
$$

where: $r_{i, t}^{E R} \equiv r_{i, t}-r_{m, t}, r_{i, t}^{M M} \equiv r_{i, t}-\left(r_{f, t}+\beta_{i, t}\left(r_{m, t}-r_{f, t}\right)\right), r_{i, t}$ is the raw return of stock $i$ in month $t, r_{m, t}$ is the monthly return of the CRSP equally weighted market portfolio, $\beta_{i, t}$ is the beta of the stock estimated over a sixty-month rolling window and $r_{f, t}$ is the risk-free rate. $\bar{r}_{i, t}^{k}$ and $\sigma_{i, t}^{k}, k=E R, M M, \emptyset$, denote the sample mean and standard deviation of the corresponding $k$ variable and are computed using a five-year rolling window. Regarding the independent variables: $I N S S A L_{i, t}-1$ are the past month insiders' sales in stock $i, I N S S A L_{i, t-2, t-12}$ is the average of the insiders sales in stock $i$ during the period $t-12$ to $t-2$, INSPURCH $H_{i, t-1}$ are the past month insiders' purchases in stock $i, I N S P U R C H_{i, t-2, t-12}$ is the average of the insiders purchases in stock $i$ during the period $t-12$ to $t-2, T T V_{i, t-1}$ is the past month total trading volume in stock $i, T T V_{i, t-2, t-12}$ is the average total trading volume in stock $i$ during the period $t-12$ to $t-2$ and $E R_{i, t-1, t-24}$ is stock's $i$ cumulative excess return over the CRSP equally weighted market portfolio for the previous two years. The sample consists of insiders open market or private sales and purchases from 1986 to 2002 in common stocks traded in NYSE, AMEX and Nasdaq markets that appear in CRSP dataset; the data on insider transactions comes from Thompson Financial Data Fillings dataset. We exclude stocks with price smaller than $\$ 2$ at the beginning of each calendar year, amended insider trading records, transactions involving less than 100 shares, and fillings in which the reported transaction price was not within $20 \%$ of the CRSP closing price on that day, or that involved more than the $20 \%$ of the number of shares outstanding. 
Table 9: Robustness checks: the probit model.

\begin{tabular}{|c|c|c|c|c|}
\hline & (1) & $(2)$ & $(3)$ & $(4)$ \\
\hline & ERCRASH & MMCRASH & ERJUMP & MMJUMP \\
\hline \multirow[t]{2}{*}{$I N S S A L_{t-1}$} & $-0.988^{*}$ & $-1.442^{*}$ & & \\
\hline & $(0.454)$ & $(0.586)$ & & \\
\hline \multirow[t]{2}{*}{$I N S S A L_{t-2, t-12}$} & $1.547^{*}$ & -0.393 & & \\
\hline & $(0.680)$ & $(0.806)$ & & \\
\hline \multirow{2}{*}{$E R_{t-1, t-24}$} & $-0.006^{*}$ & -0.002 & $-0.105^{* *}$ & $-0.102^{* *}$ \\
\hline & $(0.003)$ & $(0.002)$ & $(0.009)$ & $(0.006)$ \\
\hline \multirow[t]{2}{*}{$T T V_{t-1}$} & $0.136^{* *}$ & $0.111^{* *}$ & $0.192^{* *}$ & $0.162^{* *}$ \\
\hline & $(0.020)$ & $(0.017)$ & $(0.023)$ & $(0.020)$ \\
\hline \multirow[t]{2}{*}{$T T V_{t-2, t-12}$} & $-0.261^{* *}$ & 0.000 & $-0.398 * *$ & $-0.488^{* *}$ \\
\hline & $(0.032)$ & $(0.027)$ & $(0.038)$ & $(0.038)$ \\
\hline \multirow[t]{2}{*}{$I N S P U R C H_{t-1}$} & & & $0.517^{*}$ & $0.564^{*}$ \\
\hline & & & $(0.263)$ & $(0.269)$ \\
\hline \multirow[t]{2}{*}{ INSPURCH $H_{t-2, t-12}$} & & & 0.610 & 1.091 \\
\hline & & & $(1.067)$ & $(1.129)$ \\
\hline Observations & 789658 & 789658 & 789658 & 789658 \\
\hline \multicolumn{5}{|c|}{ Standard errors in parentheses } \\
\hline \multicolumn{5}{|c|}{+ significant at $10 \% ; *$ significant at $5 \% ; * *$ significant at $1 \%$} \\
\hline
\end{tabular}

In this table we report the estimation of the probit version of our leading regressions for crashes and jumps. In the estimation we only allow for year effects and use the Newey-West standard errors to control for autocorrelation and heteroscedasticity. The depended variables in the regressions are defined as follows:

$$
\operatorname{ERCRASH}_{i, t}=\left\{\begin{array}{ll}
1, & \text { if } r_{i, t}^{E R}-\bar{r}_{i, t}^{E R} \leq-2 \sigma_{i, t}^{E R} ; \\
0, & \text { otherwise. } \\
1, & \text { if } r_{i, t}^{M M}-\bar{r}_{i, t}^{M M} \leq-2 \sigma_{i, t}^{M M} ; \\
0, & \text { otherwise. }
\end{array} \quad \text { ERJUMP } P_{i, t}= \begin{cases}1, & \text { if } r_{i, t}^{E R}-\bar{r}_{i, t}^{E R} \geq 2 \sigma_{i, t}^{E R} ; \\
0, & \text { otherwise. } \\
1, & \text { if } r_{i, t}^{M M}-\bar{r}_{i, t}^{M M} \geq 2 \sigma_{i, t}^{M M} \\
0, & \text { otherwise. }\end{cases}\right.
$$

where: $r_{i, t}^{E R} \equiv r_{i, t}-r_{m, t}, r_{i, t}^{M M} \equiv r_{i, t}-\left(r_{f, t}+\beta_{i, t}\left(r_{m, t}-r_{f, t}\right)\right), r_{i, t}$ is the raw return of stock $i$ in month $t, r_{m, t}$ is the monthly return of the CRSP equally weighted market portfolio, $\beta_{i, t}$ is the beta of the stock estimated over a sixty-month rolling window and $r_{f, t}$ is the risk-free rate. $\bar{r}_{i, t}^{k}$ and $\sigma_{i, t}^{k}, k=E R, M M, \emptyset$, denote the sample mean and standard deviation of the corresponding $k$ variable and are computed using a five-year rolling window. Regarding the independent variables: $I N S S A L_{i, t}-1$ are the past month insiders' sales in stock $i, I N S S A L_{i, t-2, t-12}$ is the average of the insiders sales in stock $i$ during the period $t-12$ to $t-2$, INSPURCH $H_{i, t-1}$ are the past month insiders' purchases in stock $i, I N S P U R C H_{i, t-2, t-12}$ is the average of the insiders purchases in stock $i$ during the period $t-12$ to $t-2, T T V_{i, t-1}$ is the past month total trading volume in stock $i, T T V_{i, t-2, t-12}$ is the average total trading volume in stock $i$ during the period $t-12$ to $t-2$ and $E R_{i, t-1, t-24}$ is stock's $i$ cumulative excess return over the CRSP equally weighted market portfolio for the previous two years. The sample consists of insiders open market or private sales and purchases from 1986 to 2002 in common stocks traded in NYSE, AMEX and Nasdaq markets that appear in CRSP dataset; the data on insider transactions comes from Thompson Financial Data Fillings dataset. We exclude stocks with price smaller than $\$ 2$ at the beginning of each calendar year, amended insider trading records, transactions involving less than 100 shares, and fillings in which the reported transaction price was not within $20 \%$ of the CRSP closing price on that day, or that involved more than the $20 \%$ of the number of shares outstanding. 


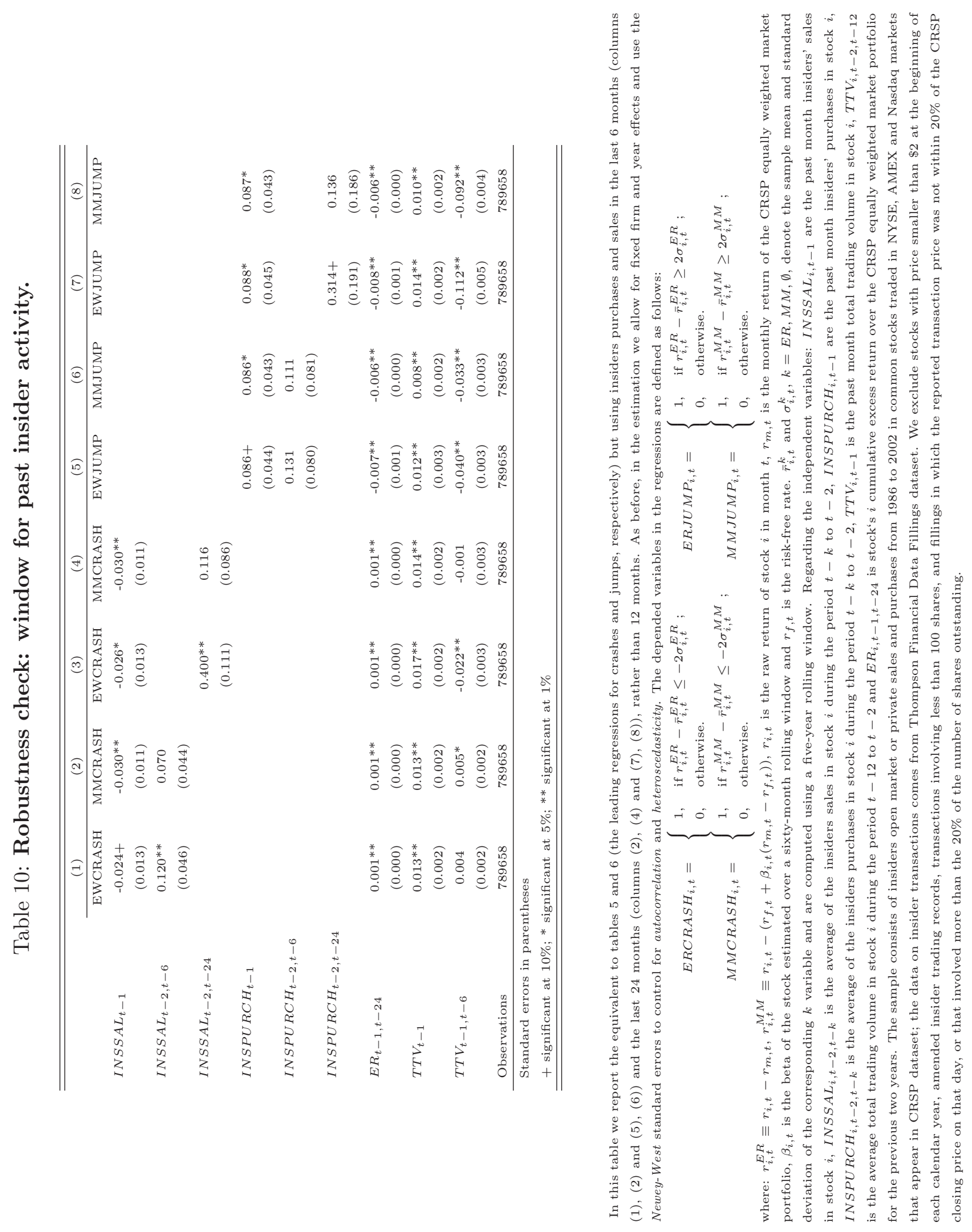




\section{Table 11: Robustness checks: large raw returns.}

\begin{tabular}{|c|c|c|}
\hline & (1) & (2) \\
\hline & RAWCRASH & RAWJUMP \\
\hline \multirow[t]{2}{*}{$I N S S A L_{t-1}$} & 0.007 & \\
\hline & $(0.017)$ & \\
\hline \multirow[t]{2}{*}{$I N S S A L_{t-2, t-12}$} & $0.343^{* *}$ & \\
\hline & $(0.070)$ & \\
\hline \multirow[t]{2}{*}{ INSPURCH $H_{t-1}$} & & $0.117^{*}$ \\
\hline & & $(0.054)$ \\
\hline \multirow[t]{2}{*}{$I N S P U R C H_{t-2, t-12}$} & & 0.117 \\
\hline & & $(0.146)$ \\
\hline \multirow[t]{2}{*}{$E R_{t-1, t-24}$} & $0.001^{* *}$ & $-0.006^{* *}$ \\
\hline & $(0.000)$ & $(0.000)$ \\
\hline \multirow[t]{2}{*}{$T T V_{t-1}$} & $0.011^{* *}$ & $0.017^{* *}$ \\
\hline & $(0.002)$ & $(0.003)$ \\
\hline \multirow[t]{2}{*}{$T T V_{t-2, t-24}$} & $0.007^{*}$ & $-0.062^{* *}$ \\
\hline & $(0.003)$ & $(0.004)$ \\
\hline Observations & 789658 & 789658 \\
\hline \multicolumn{3}{|c|}{ Standard errors in parentheses } \\
\hline \multicolumn{3}{|c|}{+ significant at $10 \%{ }^{*}$ significant at $5 \% ; * *$ significant at $1 \%$} \\
\hline
\end{tabular}

In this table we report the equivalent to tables 5 and 6 (leading regressions for crashes and jumps, respectively) but using a definition of crashes and jumps based on raw returns rather than returns in excess of the CRSP equally weighted market portfolio or the returns predicted by the market model. As before, in the estimation we allow for fixed firm and year effects and use the Newey-West standard errors to control for autocorrelation and heteroscedasticity. The depended variables in the regressions are defined as follows:

$$
R A W C R A S H_{i, t}=\left\{\begin{array}{ll}
1, & \text { if } r_{i, t}-\bar{r}_{i, t} \leq-2 \sigma_{i, t} ; \\
0, & \text { otherwise. }
\end{array} \quad \text { RAWJUMP } P_{i, t}= \begin{cases}1, & \text { if } r_{i, t}-\bar{r}_{i, t} \geq 2 \sigma_{i, t} \\
0, & \text { otherwise. }\end{cases}\right.
$$

In these expressions we have: $r_{i, t}$ is the raw return of stock $i$ in month $t, \bar{r}_{i, t}$ and $\sigma_{i, t}$, denote the sample means and standard deviations of the raw return and are computed using a five-year rolling window. Regarding the independent variables: INSSAL $L_{i, t-1}$ are the past month insiders' sales in stock $i, I N S S A L_{i, t-2, t-12}$ is the average of the insiders sales in stock $i$ during the period $t-12$ to $t-2, I N S P U R C H_{i, t-1}$ are the past month insiders' purchases in stock $i, I N S P U R C H_{i, t-2, t-12}$ is the average of the insiders purchases in stock $i$ during the period $t-12$ to $t-2, T T V_{i, t-1}$ is the past month total trading volume in stock $i, T T V_{i, t-2, t-12}$ is the average total trading volume in stock $i$ during the period $t-12$ to $t-2$ and $E R_{i, t-1, t-24}$ is stock's $i$ cumulative excess return over the CRSP equally weighted market portfolio for the previous two years. The sample consists of insiders open market or private sales and purchases from 1986 to 2002 in common stocks traded in NYSE, AMEX and Nasdaq markets that appear in CRSP dataset; the data on insider transactions comes from Thompson Financial Data Fillings dataset. We exclude stocks with price smaller than $\$ 2$ at the beginning of each calendar year, amended insider trading records, transactions involving less than 100 shares, and fillings in which the reported transaction price was not within $20 \%$ of the CRSP closing price on that day, or that involved more than the $20 \%$ of the number of shares outstanding. 
Table 12: Leading regression when no earning announcements.

\begin{tabular}{|c|c|c|c|c|}
\hline \multicolumn{5}{|c|}{ Not Earning Announcement } \\
\hline & (1) & $(2)$ & $(3)$ & (4) \\
\hline & EWCRASH & MMCRASH & EWJUMP & MMJUMP \\
\hline \multirow[t]{2}{*}{$I N S S A L_{t-1}$} & $-0.028^{*}$ & $-0.028^{* *}$ & & \\
\hline & $(0.011)$ & $(0.009)$ & & \\
\hline \multirow[t]{2}{*}{$I N S S A L_{t-2, t-12}$} & $0.274^{* *}$ & $0.156^{*}$ & & \\
\hline & $(0.086)$ & $(0.072)$ & & \\
\hline \multirow[t]{2}{*}{$I N S P U R C H_{t-1}$} & & & 0.083 & 0.080 \\
\hline & & & $(0.055)$ & $(0.051)$ \\
\hline \multirow[t]{2}{*}{$I N S P U R C H_{t-2, t-12}$} & & & 0.130 & 0.310 \\
\hline & & & $(0.227)$ & $(0.211)$ \\
\hline \multirow[t]{2}{*}{$E R_{t-1, t-24}$} & $0.001^{* *}$ & $0.001^{* *}$ & $-0.006^{* *}$ & $-0.005^{* *}$ \\
\hline & $(0.000)$ & $(0.000)$ & $(0.000)$ & $(0.000)$ \\
\hline \multirow[t]{2}{*}{$T T V_{t-1}$} & $0.015^{* *}$ & $0.012^{* *}$ & $0.015^{* *}$ & $0.010^{* *}$ \\
\hline & $(0.002)$ & $(0.002)$ & $(0.003)$ & $(0.002)$ \\
\hline \multirow[t]{2}{*}{$T T V_{t-2, t-12}$} & -0.005 & $0.009^{* *}$ & $-0.066^{* *}$ & $-0.050^{* *}$ \\
\hline & $(0.003)$ & $(0.003)$ & $(0.005)$ & $(0.004)$ \\
\hline Observations & 463395 & 463395 & 463395 & 463395 \\
\hline \multicolumn{5}{|c|}{ Standard errors in parentheses } \\
\hline \multicolumn{5}{|c|}{+ significant at $10 \% ; *$ significant at $5 \% ; * *$ significant at $1 \%$} \\
\hline
\end{tabular}

In this table we report the results of the estimation of our leading regression for crashes and jumps when these do not take place in an earning announcement month. As before, in the estimation we allow for fixed firm and year effects and use the Newey-West standard errors to control for autocorrelation and heteroscedasticity. The depended variables in the regressions are defined as follows:

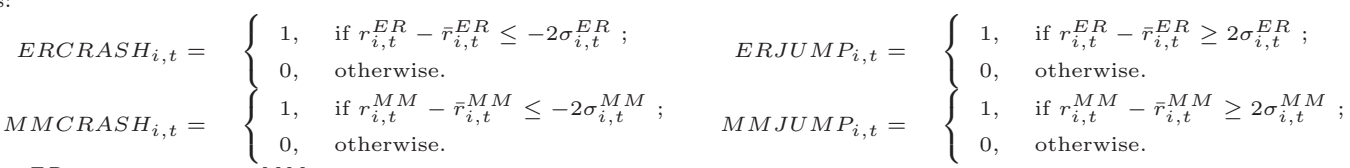

where: $r_{i, t}^{E R} \equiv r_{i, t}-r_{m, t}, r_{i, t}^{M M} \equiv r_{i, t}-\left(r_{f, t}+\beta_{i, t}\left(r_{m, t}-r_{f, t}\right)\right), r_{i, t}$ is the raw return of stock $i$ in month $t, r_{m, t}$ is the monthly return of the CRSP equally weighted market portfolio, $\beta_{i, t}$ is the beta of the stock estimated over a sixty-month rolling window and $r_{f, t}$ is the risk-free rate. $\bar{r}_{i, t}^{k}$ and $\sigma_{i, t}^{k}, k=E R, M M, \emptyset$, denote the sample mean and standard deviation of the corresponding $k$ variable and are computed using a five-year rolling window. Regarding the independent variables: $I N S S A L_{i, t}-1$ are the past month insiders' sales in stock $i, I N S S A L_{i, t-2, t-12}$ is the average of the insiders sales in stock $i$ during the period $t-12$ to $t-2, I N S P U R C H_{i, t-1}$ are the past month insiders' purchases in stock $i, I N S P U R C H_{i, t-2, t-12}$ is the average of the insiders purchases in stock $i$ during the period $t-12$ to $t-2, T T V_{i, t-1}$ is the past month total trading volume in stock $i, T T V_{i, t-2, t-12}$ is the average total trading volume in stock $i$ during the period $t-12$ to $t-2$ and $E R_{i, t-1, t-24}$ is stock's $i$ cumulative excess return over the CRSP equally weighted market portfolio for the previous two years. The sample consists of insiders open market or private sales and purchases from 1986 to 2002 in common stocks traded in NYSE, AMEX and Nasdaq markets that appear in CRSP dataset; the data on insider transactions comes from Thompson Financial Data Fillings dataset. We exclude stocks with price smaller than $\$ 2$ at the beginning of each calendar year, amended insider trading records, transactions involving less than 100 shares, and fillings in which the reported transaction price was not within $20 \%$ of the CRSP closing price on that day, or that involved more than the $20 \%$ of the number of shares outstanding. 
Table 13: Leading regression when earning announcements.

\begin{tabular}{|c|c|c|c|c|}
\hline \multicolumn{5}{|c|}{ Earning Announcement } \\
\hline & (1) & (2) & (3) & (4) \\
\hline & ERCRASH & MMCRASH & ERJUMP & MMJUMP \\
\hline \multirow{2}{*}{$I N S S A L_{t-1}$} & 0.005 & -0.032 & & \\
\hline & $(0.043)$ & $(0.039)$ & & \\
\hline \multirow[t]{2}{*}{$I N S S A L_{t-2, t-12}$} & 0.099 & 0.039 & & \\
\hline & $(0.103)$ & $(0.088)$ & & \\
\hline \multirow[t]{2}{*}{$I N S P U R C H_{t-1}$} & & & 0.118 & 0.079 \\
\hline & & & $(0.078)$ & $(0.074)$ \\
\hline \multirow{2}{*}{$I N S P U R C H_{t-2, t-12}$} & & & 0.324 & 0.050 \\
\hline & & & $(0.213)$ & $(0.176)$ \\
\hline \multirow[t]{2}{*}{$E R_{t-1, t-24}$} & $0.002^{* *}$ & $0.003^{* *}$ & $-0.008^{* *}$ & $-0.007 * *$ \\
\hline & $(0.000)$ & $(0.000)$ & $(0.001)$ & $(0.001)$ \\
\hline \multirow[t]{2}{*}{$T T V_{t-1}$} & $0.018^{* *}$ & $0.017^{* *}$ & $0.022^{* *}$ & $0.019^{* *}$ \\
\hline & $(0.004)$ & $(0.004)$ & $(0.006)$ & $(0.005)$ \\
\hline \multirow[t]{2}{*}{$T T V_{t-2, t-12}$} & -0.002 & $0.009+$ & $-0.085^{* *}$ & $-0.069^{* *}$ \\
\hline & $(0.005)$ & $(0.005)$ & $(0.008)$ & $(0.007)$ \\
\hline Observations & 224993 & 224993 & 224993 & 224993 \\
\hline \multicolumn{5}{|c|}{ Standard errors in parentheses } \\
\hline \multicolumn{5}{|c|}{+ significant at $10 \% ; *$ significant at $5 \% ; * *$ significant at $1 \%$} \\
\hline
\end{tabular}

In this table we report the results of the estimation of our leading regressions for crashes and jumps when these do take place in an earning announcement month. As before, in the estimation we allow for fixed firm and year effects and use the Newey-West standard errors to control for autocorrelation and heteroscedasticity. The depended variables in the regressions are defined as follows:

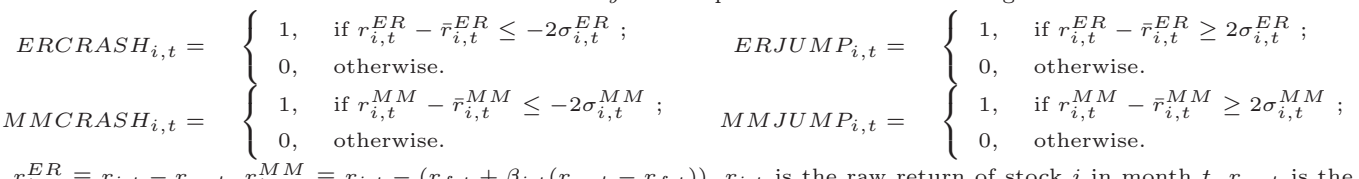

where: $r_{i, t}^{E R} \equiv r_{i, t}-r_{m, t}, r_{i, t}^{M M} \equiv r_{i, t}-\left(r_{f, t}+\beta_{i, t}\left(r_{m, t}-r_{f, t}\right)\right), r_{i, t}$ is the raw return of stock $i$ in month $t, r_{m, t}$ is the monthly return of the CRSP equally weighted market portfolio, $\beta_{i, t}$ is the beta of the stock estimated over a sixty-month rolling window and $r_{f, t}$ is the risk-free rate. $\bar{r}_{i, t}^{k}$ and $\sigma_{i, t}^{k}, k=E R, M M, \emptyset$, denote the sample mean and standard deviation of the corresponding $k$ variable and are computed using a five-year rolling window. Regarding the independent variables: $I N S S A L_{i, t-1}$ are the past month insiders' sales in stock $i, I N S S A L_{i, t-2, t-12}$ is the average of the insiders sales in stock $i$ during the period $t-12$ to $t-2$, INSPURCH $H_{i, t-1}$ are the past month insiders' purchases in stock $i, I N S P U R C H_{i, t-2, t-12}$ is the average of the insiders purchases in stock $i$ during the period $t-12$ to $t-2, T T V_{i, t-1}$ is the past month total trading volume in stock $i, T T V_{i, t-2, t-12}$ is the average total trading volume in stock $i$ during the period $t-12$ to $t-2$ and $E R_{i, t-1, t-24}$ is stock's $i$ cumulative excess return over the CRSP equally weighted market portfolio for the previous two years. The sample consists of insiders open market or private sales and purchases from 1986 to 2002 in common stocks traded in NYSE, AMEX and Nasdaq markets that appear in CRSP dataset; the data on insider transactions comes from Thompson Financial Data Fillings dataset. We exclude stocks with price smaller than $\$ 2$ at the beginning of each calendar year, amended insider trading records, transactions involving less than 100 shares, and fillings in which the reported transaction price was not within $20 \%$ of the CRSP closing price on that day, or that involved more than the $20 \%$ of the number of shares outstanding. 